\title{
Macrocyclic Binucleating $\beta$-Diketiminate Ligands and their Lithium, Aluminum, and Zinc Complexes
}

\author{
Javier Vela, Liwei Zhu, Christine J. Flaschenriem, William W. Brennessel, Rene J. \\ Lachicotte, and Patrick L. Holland \\ Department of Chemistry, University of Rochester, Rochester, NY, 14627
}

\section{Abstract}

The incorporation of rigid aromatic linkers into $\beta$-diketiminate ligands creates a binucleating scaffold that holds two metals near each other. This paper discloses the synthesis, characterization, and reactivity of $\mathrm{mBin}^{2-}$, which has a meta-substituted xylylene spacer, and $\mathrm{pBin}^{2-}$, which has a parasubstituted xylylene spacer. Lithium, aluminum, and zinc complexes of each ligand are isolated, and in some cases are characterized by X-ray crystallography. The lithium complexes are coordinated to solvent-derived THF ligands, while the zinc and aluminum complexes have alkyl ligands. Complexes of the $\mathrm{mBin}^{2-}$ ligand have an anti conformation in which the metals are on opposite sides of the macrocycle, while $\mathrm{pBin}^{2-}$ complexes prefer a syn conformation. The ${ }^{1} \mathrm{H}$ NMR spectra of the complexes demonstrate that the conformations rapidly interconvert in the lithium complexes, and less rapidly in the zinc and aluminum complexes.

\section{Introduction}

Anionic diimine ligands derived from $\beta$-diketones, termed " $\beta$-diketiminates," have served as useful Schiff base ligands in coordination chemistry for decades. ${ }^{1}$ Because they form a sixmembered ring with the metal, coordinate through strongly donating nitrogen atoms, and have an overall negative charge, they are excellent chelating ligands, despite the fact that they are not always inert to ligand-based reactions. ${ }^{2}$ Bulky $\beta$-diketiminate complexes have been especially popular recently, and have found use in a number of applications including catalysts for polymerization, ${ }^{3}$ alkane and arene activation, ${ }^{4}$ hydroamination, ${ }^{5}$ carboamination, 6 and hydrodefluorination. ${ }^{7}$ They have also been used for stabilization of CVD precursors, ${ }^{8}$ reactive metal-ligand multiple bonds, $, 9,10,11,12$ metal-metal bonds, ${ }^{13}$ and copper-dioxygen complexes. ${ }^{14}$

One of our research goals is the study of complexes with multiple iron atoms held by $\beta$ -

diketiminate ligands. ${ }^{15}$ These perform cooperative multimetallic reactions of relevance to the mechanism of iron-molybdenum nitrogenase, which has a $\mathrm{Fe}_{7} \mathrm{Mo}$ active site with $\mathrm{Fe}_{2}$ units at which $\mathrm{N}_{2}$ may be reduced. ${ }^{16}$ In order to control the spatial relationship of the open coordination sites of two metals in a bimetallic complex, ${ }^{17}$ it is reasonable to synthesize binucleating $\beta$ diketiminate ligands that can accommodate two metals. In addition to nitrogenase modeling, such ligands could be useful in manipulating other multimetallic reactions of $\beta$-diketiminate complexes. 9,18

Ligands composed of two $\beta$-diketiminate units receive increasing attention in the literature. Lee and coworkers reported a macrocyclic ligand (1) that consists of two $\beta$-diketiminate units rigidly held by an arene spacer. ${ }^{19}$ They reported $\mathrm{Cu}_{2}$ and $\mathrm{Zn}_{2}$ salts of this ligand, and 
incorporated alkyl substituents that are necessary for solubility. ${ }^{20}$ Limberg has described a xanthene-bridged binucleating ligand with two parallel binding sites (2) ${ }^{21}$ Lappert has created binucleating $\beta$-diketiminates that are linked through the backbone (3) ${ }^{22}$ Other ligands that give two adjacent metal-binding sites similar to $\beta$-diketiminates have been reported. ${ }^{23}$ Ligands with two-carbon linkers typically coordinate to a single metal like tetraazaannulenes: ${ }^{24}$ for example, 4 gives mononuclear complexes. ${ }^{25}$ However, even tetraazaannulenes can act as binucleating ligands under appropriate conditions. ${ }^{26}$

Our strategy was based on ease of synthesis, as well as the use of a rigid, tunable linker that holds two $\beta$-diketiminate units far enough apart that they cannot both coordinate to the same metal, but close enough that they can engage in cooperative reactions. A simple way to do this is by linking the arene groups of the $\beta$-diketiminate to give the ligand scaffold shown in Figure $1 .{ }^{19}$ Here, we describe the initial coordination chemistry of two new ligands of this type. Xray crystallography and NMR spectroscopy elucidate important features of the conformations of the ligands, giving insight into their suitability for bimetallic reactions.

\section{Results and Discussion}

\section{Synthesis and Characterization of Protonated Ligands}

Condensation of the ethylene glycol monoketal of 2,4-pentanedione with 1 equiv of either meta-xylylenediamine or para-xylylenediamine gives the desired ligands (Scheme 1). This condensation is preferable to the typical acid-catalyzed condensations of diketones, because no acid catalyst is required in the ligand synthesis, and the latter method gave mixtures of products. Using the method in Scheme 1, the ligands $\mathrm{mBinH}_{2}$ and $\mathrm{pBinH}_{2}$ are obtained in $89 \%$ and 59\% yield, respectively. In this notation, we refer to ligands as $\mathrm{mBin}^{2-}$ for the binucleating ligand with the 1,3-substituted arene linker, and $\mathrm{pBin}^{2-}$ for the binucleating ligand with the 1,4-substituted arene linker. In general, mBin-derived compounds are somewhat more soluble than the pBin-derived analogues.

The ${ }^{1} \mathrm{H}$ NMR spectra of $\mathrm{mBinH}_{2}$ and $\mathrm{pBinH}_{2}$ each show a singlet integrating to two protons at 4.6-4.7 ppm and another singlet integrating to two protons at $11-12 \mathrm{ppm}$, indicating that one imine on each side exists as the enamine tautomer (Figure 2). This tautomer is commonly observed in $\beta$-diketimines, because the $\mathrm{N}-\mathrm{H}$ proton of the enamine has a stabilizing hydrogen bond with the lone pair of the nearby imine (this hydrogen bond results in the downfield shift of the N-H proton). ${ }^{1}$ The infrared spectrum of each compound shows a band in the 3200-3300 $\mathrm{cm}^{-1}$ range that corresponds to stretching of this N-H bond. Despite the inherent asymmetry of the enamine/imine tautomer, the ${ }^{1} \mathrm{H}$ NMR spectrum is consistent with $D_{2 \mathrm{~h}}$ symmetry, in which there are effectively three mirror planes and $C_{2}$ axes splitting the molecule. This observation implies that the enamine/imine tautomers are equilibrating more quickly than the NMR time scale.

The solid-state structure of $\mathbf{p B i n H _ { 2 }}$ from X-ray crystallography is of sufficient quality to locate and refine the positions of the $\mathrm{N}-\mathrm{H}$ hydrogen atoms, showing that the tautomer present in the crystal has both N-H protons on the same side (Figure 3). The location of these protons is consistent with the bond localization in the NCCCN backbone (Table 1), where for example $\mathrm{N}(1)-\mathrm{C}(1)$ is about $0.04 \AA$ shorter than $\mathrm{N}(2)-\mathrm{C}(3)$. (However, as shown in the previous paragraph, the tautomers exchange rapidly in $\mathrm{CDCl}_{3}$ solution.) The bridging $\mathrm{p}$-xylylene rings are nearly parallel to the plane of the large macrocycle (dihedral angles of 2.62(2) and 10.85 $\left.(2)^{\circ}\right)$ in the solid-state structure, but these must be rapidly spinning around the $\mathrm{C}$ (aryl)-C (methylene) bonds in solution to explain the equivalence of all four aryl protons in the ${ }^{1} \mathrm{H}$ NMR spectrum. 


\section{Lithium Complexes of the Binucleating Ligands}

Addition of 2 equiv of $n$-butyllithium to solutions of the ligands in dry, degassed THF gives lithium complexes $\mathbf{m B i n L i} \mathbf{i}_{\mathbf{2}}(\mathbf{T H F})_{\mathbf{2}}$ and $\mathbf{p B i n L i} \mathbf{i}_{\mathbf{2}}(\mathbf{T H F})_{\mathbf{3}}$. The numbers of coordinated THF molecules in the formulae come from the integration of the signals for the THF protons in the ${ }^{1} \mathrm{H}$ NMR spectra of $\mathrm{C}_{6} \mathrm{D}_{6}$ solutions. The absence of the downfield $\mathrm{N}-\mathrm{H}$ resonance in the ${ }^{1} \mathrm{H}$ NMR spectrum and the absence of the $\mathrm{N}-\mathrm{H}$ stretching vibration in the IR spectrum indicate the deprotonation of the ligand to its dianionic form.

Vapor diffusion of pentane into a THF solution gives crystals suitable for X-ray diffraction analysis. The structures of $\mathbf{m B i n L i}_{\mathbf{2}}(\mathbf{T H F})_{\mathbf{4}}$ and $\mathbf{p B i n L i} \mathbf{i}_{\mathbf{2}}(\mathbf{T H F})_{\mathbf{3}}$ are shown in Figure 4 . The crystal structure of the mBin-bound complex has four molecules of THF rather than the two evident from integration of ${ }^{1} \mathrm{H}$ NMR spectra; however, the NMR spectra were of $\mathrm{C}_{6} \mathrm{D}_{6}$ solutions of crystals that had been exposed to vacuum for hours. It is reasonable to conclude that two of the THF ligands in $\mathbf{m B i n L i} \mathbf{i}_{\mathbf{2}}(\mathbf{T H F})_{\mathbf{4}}$ are held rather weakly. In $\mathbf{p B i n L} \mathbf{i}_{\mathbf{2}}(\mathbf{T H F})_{\mathbf{3}}$, on the other hand, the NMR and crystal structure both show three THF ligands to the two lithium ions.

The differences between analogous $\mathrm{C}-\mathrm{N}$ and $\mathrm{C}-\mathrm{C}$ bond lengths are much smaller than in the protonated ligand, as expected for resonance delocalization of the charge in the anionic diketiminate unit on each side of the binucleating ligand. In $\mathbf{m B i n L i} \mathbf{i}_{\mathbf{2}}(\mathbf{T H F})_{\mathbf{4}}$ each lithium atom has a pseudotetrahedral geometry with two diketiminate nitrogen atoms and the oxygen atoms of two THF ligands, while in $\mathbf{~ P B i n L \mathbf { i } _ { 2 }}$ (THF) $)_{3}$ one of the lithium atoms has only one THF ligand and a roughly trigonal planar geometry. In $\mathbf{p B i n L i} \mathbf{i}_{\mathbf{2}}(\mathbf{T H F})_{3}$, the bonds to the fourcoordinate lithium atom are significantly longer than those to the three-coordinate lithium atom. The structure of $\mathbf{m B i n L i}_{\mathbf{2}}$ (THF) $\mathbf{4}_{\mathbf{4}}$ suffers from substantial disorder in the position of the THF ligands, and could not be refined to an $R$ value below $14 \%$.

The most notable difference between the overall conformations of the lithium salts of $\mathrm{mBin}^{2-}$ and $\mathrm{pBin}^{2-}$ is in the orientation of the two diketiminatometal units. The molecules are not planar as it appears in a two-dimensional picture. Rather, the crystal structures show that the diketiminate planes are far from the plane of the macrocycle $\left(80-90^{\circ}\right.$ for

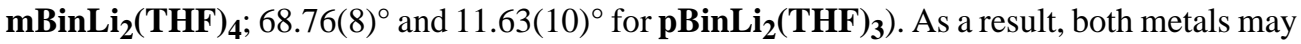
lie out of the macrocyclic plane on the same side (the syn conformation, Figure 5, left) or on opposite sides (the anti conformation, Figure 5, right). Despite the similarities in the isomeric $\mathrm{Bin}^{2-}$ ligands, $\mathbf{m B i n L i}_{\mathbf{2}}(\mathbf{T H F})_{\mathbf{4}}$ has the anti conformation, while $\mathbf{p B i n L i} \mathbf{i}_{\mathbf{2}}(\mathbf{T H F})_{\mathbf{3}}$ has the syn conformation (Figure 4). The $\mathrm{Li} \cdots \cdot \cdot \mathrm{Li}$ distance is roughly the same (6.05 $\AA$ ) in the two complexes, despite the smaller macrocyclic ring in the $\mathrm{mBin}^{2-}$ ligand. This is due to the fact that the diketiminate NCCCN planes are nearly coplanar and anti in $\mathbf{m B i n L i} \mathbf{i}_{\mathbf{2}}(\mathbf{T H F})_{\mathbf{4}}$, and nearly perpendicular (dihedral angle $80.1(1)^{\circ}$ ) and syn in $\mathbf{p B i n L i} \mathbf{i}_{\mathbf{2}}(\mathbf{T H F})_{\mathbf{3}}$.

A more careful look at the positions of atoms in these two complexes shows that the signals for the benzylic protons and for the aromatic protons give information about the dynamics of the complexes. In either the syn or anti conformation, the two geminal hydrogen atoms on each benzylic methylene carbon are inequivalent, and are expected to appear in the ${ }^{1} \mathrm{H}$ NMR spectrum as two doublets with a large coupling constant. The coupling pattern, integrations, and general location of peaks are not expected to be different for syn and anti conformers, because each has the same number of symmetry operations, and there are no obvious sources of coupling or NOE that could be exploited to learn the conformation.

In each lithium complex, the benzylic methylene protons resonate as a singlet, which implies a rapid equilibrium between syn and anti conformations on the NMR time scale. Cooling THF$d_{8}$ solutions of each lithium complex results in decoalescence of the 8-proton singlet near $\delta$ $4.5 \mathrm{ppm}$, with coalescence temperatures of $-11^{\circ} \mathrm{C}\left(\mathbf{m B i n L i}_{\mathbf{2}}(\mathbf{t h f})_{\mathbf{n}}\right)$ and $-85^{\circ} \mathrm{C}$ 
$\left(\mathbf{p B i n L i} \mathbf{i}_{\mathbf{2}}(\mathbf{t h f})_{\mathbf{n}}\right)$. This phenomenon is due to the slowing of interconversion of the conformers at lower temperature, which makes the geminal benzylic protons chemically distinct. The ${ }^{1} \mathrm{H}$ NMR spectrum of $\mathbf{m B i n L i}_{2}$ (thf) $)_{\mathbf{n}}$ in THF- $d_{8}$ at $-50{ }^{\circ} \mathrm{C}$ (well below the coalescence temperature) has two doublets $(J=15 \mathrm{~Hz})$ in this region, indicative of a single conformer, and we assume that this is the anti conformer observed in the X-ray crystal structure. The anti conformers exchange the endo/exo positions of these two protons with a barrier $\Delta \mathrm{G}^{\ddagger}=12.9 \pm$ $0.1 \mathrm{kcal} / \mathrm{mol}$.

The low-temperature ${ }^{1} \mathrm{H}$ NMR spectra of $\mathbf{p B i n L i}_{2}(\mathbf{t h f})_{\mathbf{n}}$ in THF- $d_{8}$ are more complicated. At $-85^{\circ} \mathrm{C}$, all of the peaks decoalesce into two pairs of doublets, with an integration ratio of roughly 2:1. Although the spectra are fairly broad at $-100^{\circ} \mathrm{C}$, the region near $\delta 4.5 \mathrm{ppm}$ clearly has two larger doublets and two smaller doublets, each with coupling constants near $15 \mathrm{~Hz}$ (see Supporting Information). Therefore, the spectra of $\mathbf{p B i n L} \mathbf{i}_{\mathbf{2}}(\mathbf{t h f})_{\mathbf{n}}$ are indicative of freezing the interconversion of syn and anti conformers, with a barrier $\Delta \mathrm{G}^{+}=8.9 \pm 0.3 \mathrm{kcal} / \mathrm{mol}$. In this case, one conformer is only slightly favored over the other.

Note that the four protons on each aromatic ring in the $\mathrm{pBin}^{2-}$ ligand are expected to split into two sets in either the syn (overall $C_{2 \mathrm{v}}$ symmetry; mirror plane through aromatic rings) or the anti (overall $C_{2 \mathrm{~h}}$ symmetry; $C_{2}$ axis through aromatic rings) conformation. However, these signals are observed as singlets both above and below the coalescence temperature. This behavior is consistent with the ring rapidly rotating around the two $\mathrm{C}$ (methylene)-C(aromatic) bonds on the NMR time scale, even at $-100{ }^{\circ} \mathrm{C}$.

Examination of models of both lithium complexes suggests that the syn/anti interconversion requires dissociation of THF ligands (or of diketiminate ligands) from Li. Consistent with rapid THF dissociation, we observe only one THF environment in THF- $d_{8}$ solutions of each lithium complex by ${ }^{1} \mathrm{H}$ NMR and ${ }^{13} \mathrm{C}\left\{{ }^{1} \mathrm{H}\right\}$ NMR spectroscopies. Therefore, we surmise that the lability of the THF ligands enables rapid interconversion of conformers. Because of the greater size of the macrocycle in the $\mathrm{pBin}^{-2}$ ligand, there is more room for the metals to pass by one another, and its dilithium complex can interconvert isomers with a barrier $4 \mathrm{kcal} / \mathrm{mol}$ lower than the analogous complex with the $\mathrm{mBin}^{-2}$ ligand.

\section{Aluminum Complexes of the Binucleating Ligands}

Two molar equivalents of trimethylaluminum react with $\mathbf{m B i n H}_{2}$ and with $\mathbf{p B i n H _ { 2 }}$ at room temperature in toluene to yield the complexes $\mathbf{m B i n} \mathbf{A l}_{\mathbf{2}} \mathbf{M e}_{\mathbf{4}}$ and $\mathbf{p B i n} \mathbf{A l}_{\mathbf{2}} \mathbf{M e}_{\mathbf{4}}$, respectively. Each of these complexes has been characterized by X-ray crystallographic and NMR spectroscopic techniques, which show that each aluminum atom is coordinated by two nitrogen atoms of a diketiminate unit and by two methyl groups. The $\mathrm{X}$-ray crystal structures are shown in Figure 6. Interestingly, two different crystal forms of $\mathbf{m B i n A l} \mathbf{l}_{2} \mathbf{M e}_{\mathbf{4}}$ are observed. One contains no solvent of crystallization and a crystallographic inversion center in the center of the molecule. The other crystallizes in a hexagonal lattice with a highly disordered solvent on a special position. The bond distances and angles in $\mathbf{m B i n} \mathbf{A l}_{\mathbf{2}} \mathbf{M e}_{\mathbf{4}}$ are extremely similar between the two independent crystallographic determinations (Table 3). The Al-Al distances vary somewhat (5.7630(7) and 5.612(1) $\AA$ ), but in each case, the NCCCN groups are coplanar (enforced by a crystallographic inversion center) and perpendicular to the macrocycle plane $\left(87.53(3)^{\circ}\right.$ and $\left.89.18^{\circ}\right)$.

The metrical parameters in each diketiminate-aluminum ring are similar to those in the crystallographically characterized mononuclear analogue $\left\{\mathrm{HC}(\mathrm{C}(\mathrm{Me}) \mathrm{N}(\mathrm{dipp}))_{2}\right\} \mathrm{AlMe}_{2} .{ }^{27}$ Comparison to the Cambridge Structural Database 28 shows no exceptional differences from

Supporting Information Available. Crystallographic and spectroscopic details (PDF, CIF). This material is available free of charge via the Internet at http://pubs.acs.org. 
other literature complexes of similar structure. The conformational preferences of the macrocycle differ depending on which binucleating ligand is present: $\mathbf{m B i n} \mathbf{A l}_{\mathbf{2}} \mathbf{M} \mathbf{e}_{\mathbf{4}}$ has the anti conformation while $\mathbf{p B i n} \mathbf{A l}_{\mathbf{2}} \mathbf{M e}_{\mathbf{4}}$ has a syn conformation. Note that each of these has the same conformation observed in the crystal structure of its lithium analogue, suggesting that the conformational preferences are determined by the ligand, not the choice of metal. In contrast to the lithium complexes above, the $\mathrm{mBin}^{2-}$ ligand holds the $\mathrm{Al}$ atoms closer together (5.6$5.8 \AA$ ) than the $\mathrm{pBin}^{2-}$ ligand $(7.555(1) \AA$ ) , despite the fact that the metal atoms are on opposite sides of the macrocyclic ring in the $\mathrm{mBin}^{2-}$ compound.

Another important difference involves the dynamic behavior of the complexes in solution. In contrast with the lithium salts, the conformation of each aluminum complex is locked: at room temperature the benzylic methylene protons resonate as two doublets with a geminal coupling constant of $J=15 \pm 1 \mathrm{~Hz}$. Consistent with a locked conformation, the two aluminum-bound methyl groups are inequivalent in the ${ }^{1} \mathrm{H}$ NMR spectra of each complex, where two resonances are observed upfield of TMS. ${ }^{29}$ Because a rapid equilibrium between syn and anti conformations would render these methyl groups equivalent in the NMR spectrum, we conclude that the conformations are locked (at least on the NMR time scale) in each complex. We cannot distinguish syn from anti on the basis of NMR spectroscopy, and so we assume that the crystallographically observed conformation is dominant in solution. Therefore, the crystallographic and NMR data indicate that analogous bis(dimethylaluminum) complexes of $\mathrm{mBin}^{2-}$ and $\mathrm{pBin}^{2-}$ have different conformations, and that these conformations are static on the time scale of the NMR experiment. In $\mathbf{p B i n A l} \mathbf{A}_{2} \mathbf{M e}_{4}$, all of the aromatic protons resonate at the same frequency, showing that the aromatic rings of the para-xylylene linker are again spinning rapidly around the axis defined by the two para substituents.

\section{Zinc Complexes of the Binucleating Ligands}

Assemblies of cooperating $\mathrm{Zn}^{2+}$ ions form the active site of many hydrolytic enzymes. ${ }^{30}$ Recent attention has come from multimetallic mechanisms for $\mathrm{Zn}^{2+}$-catalyzed alternating copolymerization of epoxides with $\mathrm{CO}_{2}, 3 \mathrm{~g}$ and multimetallic strategies for detecting biological $\mathrm{Zn}^{2+} .31$ Therefore, dizinc complexes of the Bin ligands are of interest. Diethylzinc reacts with with $\mathbf{~ m B i n H}_{2}$ and with $\mathbf{p B i n H}_{2}$ to eliminate ethane at room temperature in toluene. The products are $\mathbf{m B i n Z n _ { 2 }} \mathbf{E t}_{\mathbf{2}}$ and $\mathbf{p B i n Z n _ { 2 }} \mathbf{E t}_{\mathbf{2}}$, neither of which yielded single crystals suitable for X-ray diffraction analysis. They are characterized by NMR, IR and elemental analysis, as well as the crystal structure of a pyridine derivative of $\mathbf{m B i n Z n}_{2} \mathbf{E t}_{\mathbf{2}}$ (see below).

The ${ }^{1} \mathrm{H}$ NMR spectrum of $\mathbf{p B i n Z \mathbf { n } _ { 2 }} \mathbf{E t}_{\mathbf{2}}$ is indicative of a single conformation, because the geminal benzylic methylene protons are inequivalent (as in the aluminum complexes above). However, as discussed above, the NMR spectra do not distinguish between syn and anti conformations. Given the syn conformations observed in the X-ray crystal structures of the complexes of $\mathrm{pBin}^{2-}$ with both lithium and aluminum, we speculate (without definitive evidence) that a syn conformation is also dominant for its zinc complex.

Interestingly, the ${ }^{1} \mathrm{H}$ NMR spectrum of $\mathbf{m B i n Z} \mathbf{n}_{2} \mathbf{E t}_{2}$ has two sets of protons in a ratio of approximately 2:1. Each set has equivalent relative integrations of Bin and ethyl signals, indicating that both compounds are doubly metallated. The ${ }^{1} \mathrm{H}$ NMR spectrum defied assignment in the 4-5 ppm region (see Supporting Information for the spectrum), suggesting the presence of overlapping peaks with second-order coupling. It is not surprising to find second-order coupling, because the geminal coupling constant in other complexes was ${ }^{2} J \sim 15$ $\mathrm{Hz}$, which could be greater than the difference in chemical shifts between coupled protons. The observation of coupling strongly suggests that the two compounds in the $\mathbf{m B i n}_{\mathbf{Z n}} \mathbf{E}_{\mathbf{2}} \mathbf{\mathbf { t } _ { \mathbf { 2 } }}$ mixture are conformationally locked on the NMR time scale, and it is most reasonable (based on the analogous lithium and aluminum compounds) to conclude that the two are the syn and anti conformers. The ratio of the two sets of signals in a solution of $\mathbf{m B i n Z n _ { 2 }} \mathbf{E t}_{\mathbf{2}}$ changed from 
$\sim 2: 1$ to $\sim 1: 1$ upon heating from room temperature to $90{ }^{\circ} \mathrm{C}$, indicating that the conformers interconvert in a longer time regime.

In order to characterize the complexes in more detail, the reactions of $\mathrm{mBinH}_{2}$ and of $\mathrm{pBinH}_{2}$ with $\mathrm{ZnEt}_{2}$ have been performed in the presence of pyridine, yielding white solids $\mathbf{m B i n Z n}_{2} \mathbf{E t}_{\mathbf{2}} \mathbf{p y}_{\mathbf{2}}$ and $\mathbf{p B i n Z n _ { 2 }} \mathbf{E t}_{2} \mathbf{p y}_{\mathbf{2}}$. These are analogous to dizinc complexes of $\mathbf{1}$ reported by Lee and coworkers. ${ }^{19}$ Excess pyridine does not change the chemical shifts of the peaks for the zinc complex, indicating that the binding of pyridine is weak. Consistent with this idea, repeated washing of the solid with pentane typically removed the pyridine from the complexes, as shown by ${ }^{1} \mathrm{H}$ NMR spectroscopy.

Fortunately, we were able to grow a crystal of $\mathbf{m B i n Z n}_{2} \mathbf{E t}_{2}$ in the presence of pyridine, which gave the structure shown in Figure 7. Relevant metrical parameters are in Table 4. The binucleating ligand is in the anti conformation, as seen for the other complexes of the $\mathrm{mBin}^{2-}$ ligand. The pyridine ligands are on the sides of the zinc atoms furthest from the neighboring zinc, presumably for steric reasons. The geometry at zinc is best described as a trigonal pyramid with the pyridine in the axial position and the the ethyl group in an equatorial position. The small influence of the pyridine ligand on the trigonal-planar (diketiminate) $\mathrm{ZnEt}$ unit is consistent with the weak binding evident from ${ }^{1} \mathrm{H}$ NMR spectra (see above). The two diketiminate ligands are coplanar (as a result of a crystallographic inversion center), and are perpendicular to the macrocycle $\left(89.96(7)^{\circ}\right)$.

The structure of $\mathbf{m B i n Z \mathbf { n } _ { 2 }} \mathbf{E t}_{\mathbf{2}} \mathbf{p y}_{\mathbf{2}}$ may be compared directly to the ethylzinc-pyridine complex of the binucleating ligand $\mathbf{1}$ (see above). ${ }^{19}$ In that structure, trigonal pyramidal zinc atoms are also evident. The sum of C14-Zn1-N21, N11-Zn1-N21, and C14-Zn1-N11 angles in $\mathbf{m B i n Z n}_{2} \mathbf{E t}_{2} \mathbf{p y}_{\mathbf{2}}$ is $349.4^{\circ}$, similar to that in the $\mathrm{Zn}_{2} \mathrm{Et}_{2}(\mathrm{py})_{2}$ complex of $\mathbf{1}\left(346.9^{\circ}\right)$. The $\mathrm{Zn}$ $\mathrm{Zn}$ distance in $\mathbf{m B i n Z \mathbf { n } _ { 2 }} \mathbf{E t}_{2} \mathbf{p y}_{\mathbf{2}}$ is 5.2435(9) $\AA$; presumably the fact that the apexes of the trigonal pyramids face the outside of the molecule allows the metal atoms to approach each other more closely than in the $\mathrm{Li}$ and $\mathrm{Al}$ complexes described above. Notice that the $\mathrm{Zn}-\mathrm{Zn}$ distance is substantially shorter than in the analogous complex of binucleating ligand $\mathbf{1}$ (6.01 $\AA$, no esd reported). 19

\section{Conformational Preferences of the Bin Ligands}

Lee and coworkers have found that the zinc(II)-and copper(I)-benzene complexes of the aryllinked bis-diketiminate ligand 1 display the anti conformation. ${ }^{19}$ Complexes of the Bin ligands display more variable conformations. In every case where the conformation of the bimetallic complexes is known from crystallography, the preferred conformation of $\mathrm{mBin}^{2-}$ complexes is anti, and that of $\mathrm{pBin}^{2-}$ complexes is syn. Because the meta-xylylene linker constrains the two metal centers to be relatively close, steric effects are the most likely explanation for the anti preference of $\mathrm{mBin}^{2-}$ complexes. Consistent with this idea, the diketiminate rings are always coplanar, and perpendicular to the macrocycle plane. By adopting the anti conformation, the tetrahedral metal centers are able to avoid placing the non-diketiminate ligands too near one another, which would require destabilizing distortions in the syn conformation. Unfortunately, the anti conformation is not desired for cooperative reactivity between the metal centers, because the available coordination sites on the two metals are far from one another. However, there is some hope for cooperative reactivity, because ${ }^{1} \mathrm{H}$ NMR evidence suggests that $\mathbf{m B i n Z} \mathbf{n}_{2} \mathbf{E t}_{\mathbf{2}}$ partially populates the syn conformer.

It is more difficult to explain why $\mathrm{pBin}^{2-}$ complexes prefer the syn conformation. The metals are on the same side of the macrocycle in crystals of $\mathrm{pBin}^{2-}$ complexes of lithium and aluminum, suggesting that the syn preference may be a general phenomenon. This contrasts with ligand $\mathbf{1}$, which gave the anti conformer in both copper(I) and zinc(II) complexes. It is especially interesting that the crystal structure of $\mathbf{p B i n L i}_{\mathbf{2}}(\mathbf{T H F})_{\mathbf{3}}$ clearly shows a preference 
for the syn conformer despite (presumably) destabilizing nonbonded interactions between the THF ligands on the two lithium centers. This promising feature of $\mathrm{pBin}^{2-}$ is tempered by the long (> $6 \AA$ ) distance between two metal centers in crystallographically characterized $\mathrm{pBin}^{2-}$ complexes. Future work will aim at ligands with a preference for the syn conformation, and a shorter intermetallic distance that encourages cooperative reactions of bimetallic complexes.

\section{Experimental Section}

\section{General considerations}

Manipulations were performed under an $\mathrm{N}_{2}$ atmosphere by standard Schlenk techniques or in an M. Braun Unilab $\mathrm{N}_{2}$-filled glove box maintained at or below 1 ppm of $\mathrm{O}_{2}$ and $\mathrm{H}_{2} \mathrm{O}$.

Glassware was dried at $150{ }^{\circ} \mathrm{C}$ overnight. Proton and carbon-13 NMR data were recorded on a Bruker Avance 400 spectrometer $\left(400 \mathrm{MHz}\right.$ for ${ }^{1} \mathrm{H} ; 101 \mathrm{MHz}$ for $\left.{ }^{13} \mathrm{C}\right)$ at the specified temperature. Chemical shifts $(\delta)$ are reported in ppm, relative to residual protiated solvent in benzene- $d_{6}(7.15)$, THF- $d_{8}(3.58,1.73)$, or $\mathrm{CDCl}_{3}(7.27)$. IR spectra $\left(450-4000 \mathrm{~cm}^{-1}\right)$ were recorded on $\mathrm{KBr}$ pellets in a Shimadzu FTIR spectrophotometer (FTIR 8400S), and the spectra are shown in the Supporting Information. A total of 32 scans at a $2 \mathrm{~cm}^{-1}$ resolution were collected in each case. Microanalysis was performed by Desert Analytics (Tucson, AZ). Pentane, diethyl ether, tetrahydrofuran (THF), and toluene were purified by passage through activated alumina and "deoxygenizer" columns from Glass Contour Company (Laguna Beach, CA). Deuterated benzene and tetrahydrofuran were vacuum distilled from sodiumbenzophenone ketyl into a storage container or directly into the NMR tube. Benzene, ethanol, ethylene glycol (Fisher), and n-butyllithium (2.5 M in hexane), trimethylaluminum ( $2 \mathrm{M}$ in hexane), diethylzinc (1.0 M in hexane), 2,4-pentanedione, p-toluenesulfonic acid monohydrate, $m$-xylylenediamine and $p$-xylylenediamine were purchased from Aldrich and used as received.

\section{2,4-Pentanedione-2,2-(ethyleneglycol) monoketal}

This procedure was slightly modified from the literature. ${ }^{32}$ A mixture of 2,4-pentanedione (20.0 g, $200 \mathrm{mmol})$, ethylene glycol (12.4 g, $200 \mathrm{mmol})$ and p-toluenesulfonic acid monohydrate $(43 \mathrm{mg}, 0.23 \mu \mathrm{mol})$ was refluxed in benzene $(40 \mathrm{~mL})$ for $3 \mathrm{~d}$ with azeotropic removal of water. After concentration under reduced pressure at room temperature, distillation under static vacuum $\left(5 \mathrm{mbar}, 120^{\circ} \mathrm{C}\right)$ afforded a colorless liquid: $20.2 \mathrm{~g}$, $70 \%$ yield. The presence of substantial impurities in some cases did not affect the purity of subsequent reactions; the ${ }^{1} \mathrm{H}$ NMR spectrum of a typical monoketal-containing mixture is given in the Supporting Information. The following peaks correspond to the monoketal: ${ }^{1} \mathrm{H}$ NMR $\left(\mathrm{C}_{6} \mathrm{D}_{6}\right.$, $20^{\circ} \mathrm{C}$ ): $3.94\left(\mathrm{~d}, 4 \mathrm{H},-\mathrm{CH}_{2}-\mathrm{CH}_{2}-\right), 2.73\left(\mathrm{~s}, 2 \mathrm{H},-\mathrm{CH}_{2}-\right), 2.19\left(\mathrm{~s}, 3 \mathrm{H}, \mathrm{CH}_{3}\right), 1.38\left(\mathrm{~s}, 3 \mathrm{H}, \mathrm{CH}_{3}\right)$.

\section{$\mathrm{mBinH}_{2}$}

meta-Xylylenediamine (425 mg, $3.12 \mathrm{mmol}$ ) and 2,4-pentanedione ethylene glycol monoketal $(450 \mathrm{mg}, 3.12 \mathrm{mmol})$ were placed in a resealable tube. The mixture was stirred and heated to $100{ }^{\circ} \mathrm{C}$ for $2 \mathrm{~h}$ and then allowed to cool to room temperature. Pre-cooled ethanol $\left(\mathrm{ca} .0^{\circ} \mathrm{C}\right)$ was then added and the mixture was further stirred at room temperature for $12 \mathrm{~h}$, after which a white solid precipitated. This solid was collected by filtration: $554 \mathrm{mg}$, $89 \%$. Analysis found (calcd.) C, $77.81(77.96) \%, \mathrm{H}, 7.93(8.05) \%, \mathrm{~N}, 14.06(13.99) \% ;{ }^{1} \mathrm{H} \mathrm{NMR}\left(\mathrm{CDCl}_{3}, 21{ }^{\circ} \mathrm{C}\right.$, see labeling scheme below): 11.60 (s, 2H, NH), 7.44 (s, 2H, 2- ArCH), 7.19 (t, 2H, 4-ArCH, J = $7.2 \mathrm{~Hz}$ ), 7.07 (d, 4H, 3-ArCH, J = 7.2 Hz), $4.60(\mathrm{~s}, 2 \mathrm{H}, \alpha-\mathrm{CH}), 4.56\left(\mathrm{~s}, 8 \mathrm{H}, \mathrm{CH}_{2}\right), 1.92(\mathrm{~s}, 12 \mathrm{H}$, $\left.\mathrm{CH}_{3}\right) \cdot{ }^{13} \mathrm{C}\left\{{ }^{1} \mathrm{H}\right\} \mathrm{NMR}\left(\mathrm{CDCl}_{3}, 21^{\circ} \mathrm{C}\right): 161.6(\mathrm{C}=\mathrm{N}), 143.2$ (aryl), 128.4 (aryl), 126.8 (aryl), 126.3 (aryl), $95.37(\alpha-\mathrm{C}), 51.19\left(\mathrm{CH}_{2}\right), 19.46\left(\mathrm{CH}_{3}\right)$. APCI+-MS $(\mathrm{m} / \mathrm{z}): 401.3[\mathrm{M}+\mathrm{H}]^{+}$. The IR spectrum is included in the Supporting Information. 


\section{$\mathrm{pBinH}_{2}$}

para-Xylylenediamine (2.04 g, $15.0 \mathrm{mmol})$ and 2,4-pentanedione-2,2-(ethyleneglycol) monoketal $(2.60 \mathrm{~g}, 18.0 \mathrm{mmol})$ were placed in a resealable Schlenk flask containing a magnetic stir bar and the flask was closed. The mixture was then stirred and heated to $100^{\circ} \mathrm{C}$ for $30 \mathrm{~min}$. The liquid phase was allowed to cool to room temperature and pre-cooled ethanol $\left(\mathrm{ca} .0^{\circ} \mathrm{C}\right)$ was added, causing the immediate precipitation of a white solid that was collected by filtration on a medium frit. Traces of solvent were removed under vacuum overnight: $1.76 \mathrm{~g}, 58.7 \%$. Analysis found (calcd.) C, 77.91 (77.96)\%, H, 8.07 (8.05)\%, N, 14.01 (13.99)\%; ${ }^{1} \mathrm{H}$ NMR $\left(\mathrm{CDCl}_{3}, 21^{\circ} \mathrm{C}\right): 11.15$ (s, 2H, NH), $7.13(\mathrm{~s}, 8 \mathrm{H}, \operatorname{aryl}), 4.67(\mathrm{~s}, 2 \mathrm{H}, \alpha-\mathrm{CH}), 4.40\left(\mathrm{~s}, 8 \mathrm{H}, \mathrm{CH}_{2}\right)$, $2.00\left(\mathrm{~s}, 12 \mathrm{H}, \mathrm{CH}_{3}\right) .{ }^{13} \mathrm{C}\left\{{ }^{1} \mathrm{H}\right\}$ NMR (THF- $\left.d_{8}, 21^{\circ} \mathrm{C}\right): 159.8(\mathrm{C}=\mathrm{N}), 138.5$ (aryl), 127.3 (aryl), $94.6(\alpha-\mathrm{C}), 50.5\left(\mathrm{CH}_{2}\right), 19.5\left(\mathrm{CH}_{3}\right)$. APCI+-MS $(\mathrm{m} / \mathrm{z}): 401.2[\mathrm{M}+\mathrm{H}]^{+}$. The IR spectrum is included in the Supporting Information.

\section{$\mathrm{mBinLi}_{2}(\mathrm{THF})_{2}$}

$n$-Buthyllithium $(0.80 \mathrm{~mL}$ of a $2.5 \mathrm{M}$ solution in hexanes, $2.0 \mathrm{mmol})$ was added to a stirred solution of $\mathrm{mBinH}_{2}(400 \mathrm{mg}, 1.00 \mathrm{mmol})$ in THF $(25 \mathrm{~mL})$ at room temperature, and stirring was continued for $12 \mathrm{~h}$. The solution was then concentrated to $7 \mathrm{~mL}$ and cooled to $-38{ }^{\circ} \mathrm{C}$, to give needles of $m \mathrm{BinLi}_{2} \mathrm{THF}$ (389mg, 68.8\%). Analysis found (calcd.) C, $70.14(73.36) \%, \mathrm{H}$, $7.87(8.33) \%, \mathrm{~N}, 10.07(10.65) \% .{ }^{1} \mathrm{H}$ NMR $\left(\mathrm{C}_{6} \mathrm{D}_{6}, 21^{\circ} \mathrm{C}\right): 7.51(\mathrm{~s}, 2 \mathrm{H}, 2-\mathrm{ArCH}), 7.04(\mathrm{t}, 2 \mathrm{H}$, 4-ArCH, J = 7.2 Hz), $6.95(\mathrm{~d}, 4 \mathrm{H}, 3-\mathrm{ArCH}, \mathrm{J}=7.3 \mathrm{~Hz}), 4.62\left(\mathrm{~s}, 8 \mathrm{H}, \mathrm{CH}_{2}\right), 4.48(\mathrm{~s}, 2 \mathrm{H}, \alpha-\mathrm{CH})$, $3.28\left(\mathrm{t}, 8 \mathrm{H}, \alpha-\mathrm{CH}_{2}\right.$ of THF, $\left.6 \mathrm{~Hz}\right), 1.95\left(\mathrm{~s}, 12 \mathrm{H}, \mathrm{CH}_{3}\right), 1.21\left(\mathrm{~m}, 8 \mathrm{H}, \beta-\mathrm{CH}_{2}\right.$ of THF). ${ }^{13} \mathrm{C}\left\{{ }^{1} \mathrm{H}\right\}$ NMR (THF- $\left.d_{8}, 21^{\circ} \mathrm{C}\right): 164.3(\mathrm{C}=\mathrm{N}), 145.1$ (aryl), 126.3 (aryl), 125.3 (aryl), 124.0 (aryl), 92.1 $(\alpha-\mathrm{C}), 54.5\left(\mathrm{CH}_{2}\right), 20.4\left(\mathrm{CH}_{3}\right)$. The IR spectrum is included in the Supporting Information.

\section{$\mathrm{mBinAl}_{2} \mathrm{Me}_{4}$}

Trimethylaluminum $(0.30 \mathrm{~mL}$ of a $2 \mathrm{M}$ solution in hexane, $0.60 \mathrm{mmol})$ was added to a solution of $\mathrm{mBinH}_{2}(120 \mathrm{mg}, 0.30 \mathrm{mmol})$ in a mixture of toluene $(4 \mathrm{~mL})$ and THF $(4 \mathrm{~mL})$ at room temperature. After stirring for $12 \mathrm{~h}$, the solution was concentrated to $3.5 \mathrm{~mL}$ and cooled to $38{ }^{\circ} \mathrm{C}$ to give white crystals (117 mg, 77\%). Analysis found (calcd.) C, $69.68(70.29) \%, \mathrm{H}$, $8.45(8.26) \%, \mathrm{~N}, 10.82(10.93) \%$; ${ }^{1} \mathrm{H}$ NMR (THF- $\left.d_{8}, 21^{\circ} \mathrm{C}\right): 7.67$ (s, $\left.2 \mathrm{H}, 2-\mathrm{ArCH}\right), 7.04(\mathrm{t}$, $2 \mathrm{H}, 4-\mathrm{ArCH}, \mathrm{J}=7.6 \mathrm{~Hz}), 6.73(\mathrm{~d}, 4 \mathrm{H}, 3-\mathrm{ArCH}, \mathrm{J}=7.2 \mathrm{~Hz}), 4.58(\mathrm{~s}, 2 \mathrm{H}, \alpha-\mathrm{CH}), 4.52(\mathrm{~d}, 4 \mathrm{H}$, $\left.\mathrm{CH}_{2}, \mathrm{~J}=16.4 \mathrm{~Hz}\right), 4.04\left(\mathrm{~d}, 4 \mathrm{H}, \mathrm{CH}_{2}, \mathrm{~J}=16.4 \mathrm{~Hz}\right) 1.46\left(\mathrm{~s}, 12 \mathrm{H}, \mathrm{CH}_{3}\right),-0.27\left(\mathrm{~s}, 6 \mathrm{H}, \mathrm{AlCH}_{3}\right)$, $-0.45\left(\mathrm{~s}, 6 \mathrm{H}, \mathrm{AlCH}_{3}\right) .{ }^{13} \mathrm{C}\left\{{ }^{1} \mathrm{H}\right\}$ NMR (THF- $\left.d_{8}, 21^{\circ} \mathrm{C}\right): 171.5(\mathrm{C}=\mathrm{N}), 142.1$ (aryl), 128.9 (aryl), 126.2 (aryl), 124.7 (aryl), $98.4(\alpha-\mathrm{C}), 51.1\left(\mathrm{Bn}-\mathrm{CH}_{2}\right), 21.8\left(\mathrm{CH}_{3}\right),-9.6\left(\mathrm{AlCH}_{3}\right),-10.0$ $\left(\mathrm{AlCH}_{3}\right)$. The IR spectrum is included in the Supporting Information.

\section{$m B i n Z n_{2} E_{2}$}

Diethylzinc $(0.3 \mathrm{~mL}, 0.3 \mathrm{mmol})$ was added to a solution of $\mathrm{mBinH}_{2}(60 \mathrm{mg}, 0.15 \mathrm{mmol})$ in toluene $(6 \mathrm{~mL})$ at room temperature. After stirring overnight, the solvent was removed under vacuum and the product was washed with pentane $(6 \mathrm{~mL})$ to produce a powder $(65.0 \mathrm{mg}$, 73.8\%). Analysis found (calcd.) C, 61.38 (61.90)\%, H, 7.00 (7.04)\%, N, $9.48(9.31) \%$. The ${ }^{1} \mathrm{H}$ NMR of this compound contains two sets of signals (in a 2:1 ratio) that are each consistent with either anti or syn conformation. ${ }^{1} \mathrm{H}$ NMR $\left(\mathrm{C}_{6} \mathrm{D}_{6}, 21^{\circ} \mathrm{C}\right)$ : major set, 7.46-6.86 (m, 8H, ArCH), 4.70-4.61 (m, 6H, $\alpha-\mathrm{CH}$ and $\left.\mathrm{CH}_{2}\right), 4.40\left(\mathrm{~d}, 4 \mathrm{H}, \mathrm{CH}_{2}, \mathrm{~J}=15.8 \mathrm{~Hz}\right), 1.70$ (s, $\left.12 \mathrm{H}, \mathrm{CH}_{3}\right), 1.28\left(\mathrm{t}, 6 \mathrm{H}, \mathrm{ZnEt}-\mathrm{CH}_{3}, \mathrm{~J}=8.0 \mathrm{~Hz}\right), 0.48\left(\mathrm{q}, 4 \mathrm{H}, \mathrm{ZnEt}-\mathrm{CH}_{2}, \mathrm{~J}=8.0 \mathrm{~Hz}\right)$; Minor set, 7.46-6.86 (m, 8H, $\mathrm{ArCH}), 4.70-4.61(\mathrm{~m}, 6 \mathrm{H}, \alpha-\mathrm{CH}$ and $\mathrm{CH} 2), 4.52\left(\mathrm{~d}, 4 \mathrm{H}, \mathrm{CH}_{2}, \mathrm{~J}=16.0\right.$ $\mathrm{Hz}$ ), $1.67\left(\mathrm{~s}, 12 \mathrm{H}, \mathrm{CH}_{3}\right), 1.23$ (t, $6 \mathrm{H}, \mathrm{ZnEt}-\mathrm{CH}_{3}, \mathrm{~J}=8.0 \mathrm{~Hz}$ ), 0.32 (q, 4H, ZnEt-CH $2, \mathrm{~J}=8.0$ $\mathrm{Hz})$. The ${ }^{13} \mathrm{C}\left\{{ }^{1} \mathrm{H}\right\}$ spectrum was very complicated because of the mixture of isomers and the limited solubility. The IR spectrum is included in the Supporting Information. 


\section{$m B i n Z n_{2} E_{2} p_{2}$}

Diethylzinc (1 mL, $1 \mathrm{mmol})$ and pyridine (10-20 drops, excess) were added to a solution of $\mathrm{mBinH}_{2}(200 \mathrm{mg}, 0.490 \mathrm{mmol})$ in toluene $(10 \mathrm{~mL})$ at room temperature. After stirring overnight, the solution was concentrated to $4 \mathrm{~mL}$ and cooled to $-38^{\circ} \mathrm{C}$, causing the formation of colorless block-like crystals ( $230 \mathrm{mg}, 61 \%$ ). Analysis found (calcd.) C, $63.98(64.43) \%, \mathrm{H}$, $6.91(6.76) \%, \mathrm{~N}, 11.19(11.27) \%$. ${ }^{1} \mathrm{H}$ NMR: major set, $8.50(\mathrm{~d}, 4 \mathrm{H}$, py $o-\mathrm{ArCH}, \mathrm{J}=4.4 \mathrm{~Hz})$, 7.50-6.87(m, $8 \mathrm{H}, \mathrm{ArCH}), 6.95(\mathrm{t}, 2 \mathrm{H}$, py $p-\mathrm{ArCH}, \mathrm{J}=7.6 \mathrm{~Hz}), 6.64(\mathrm{~m}, 4 \mathrm{H}$, py $m-\mathrm{ArCH})$, 4.80-4.71(m, $6 \mathrm{H}, \alpha-\mathrm{CH}$ and $\left.-\mathrm{CH}_{2}\right), 4.42\left(\mathrm{~d}, 4 \mathrm{H},-\mathrm{CH}_{2}, \mathrm{~J}=16 \mathrm{~Hz}\right), 1.72\left(\mathrm{~s}, 12 \mathrm{H}, \mathrm{CH}_{3}\right), 1.31(\mathrm{t}$, $6 \mathrm{H}, \mathrm{ZnEt}-\mathrm{CH}_{3}, \mathrm{~J}=8 \mathrm{~Hz}$ ), 0.50 (q, 4H, ZnEt-CH $2, \mathrm{~J}=8 \mathrm{~Hz}$ ); minor set, 8.50 (d, $4 \mathrm{H}$, py $o-\mathrm{ArCH}$, $\mathrm{J}=4.4 \mathrm{~Hz}), 7.50-6.87(\mathrm{~m}, 8 \mathrm{H}, \mathrm{ArCH}), 6.95(\mathrm{t}, 2 \mathrm{H}$, py $p-\mathrm{ArCH}, \mathrm{J}=7.6 \mathrm{~Hz}), 6.64(\mathrm{~m}, 4 \mathrm{H}$, py $m-$ $\mathrm{ArCH}), 4.80-4.71\left(\mathrm{~m}, 6 \mathrm{H}, \alpha-\mathrm{CH}\right.$ and $\left.-\mathrm{CH}_{2}\right), 4.52(\mathrm{~d}, 2 \mathrm{H},-\mathrm{CH} 2, \mathrm{~J}=16 \mathrm{~Hz}), 1.69\left(\mathrm{~s}, 12 \mathrm{H}, \mathrm{CH}_{3}\right)$, $1.25\left(\mathrm{t}, 6 \mathrm{H}, \mathrm{ZnEt}-\mathrm{CH}_{3}, \mathrm{~J}=8 \mathrm{~Hz}\right), 0.37\left(\mathrm{q}, 4 \mathrm{H}, \mathrm{ZnEt}-\mathrm{CH}_{2}, \mathrm{~J}=8 \mathrm{~Hz}\right)$. The ${ }^{13} \mathrm{C}\left\{{ }^{1} \mathrm{H}\right\}$ spectrum was very complicated because of the mixture of isomers and the limited solubility. The IR spectrum is included in the Supporting Information.

\section{$\mathrm{pBinLi}_{2}(\mathrm{THF})_{3}$}

$n$-Buthyllithium ( $0.8 \mathrm{~mL}$ of a $2.5 \mathrm{M}$ solution in hexanes, $2.0 \mathrm{mmol})$ was added to $\mathrm{pBinH}_{2}(0.40$ $\mathrm{g}, 1.0 \mathrm{mmol})$ in THF $(6 \mathrm{~mL})$ at room temperature and stirred for $12 \mathrm{~h}$. The solution was concentrated to $2.5 \mathrm{~mL}$ and cooled to $-38^{\circ} \mathrm{C}$, giving colorless plates ( $403 \mathrm{mg}, 64 \%$ yield). Analysis found (calcd.) C, 72.01 (72.59)\%, H, 8.41 (8.66)\%, N, $8.76(8.91) \% ;{ }^{1} \mathrm{H}$ NMR $\left(\mathrm{C}_{6} \mathrm{D}_{6}, 21^{\circ} \mathrm{C}\right): 7.35(\mathrm{~s}, 8 \mathrm{H}, \mathrm{ArCH}), 4.74(\mathrm{~s}, 2 \mathrm{H}, \alpha-\mathrm{CH}), 4.46\left(\mathrm{~s}, 8 \mathrm{H}, \mathrm{BnCH}_{2}\right), 3.27(\mathrm{~m}, 12 \mathrm{H}, \alpha-$ $\mathrm{CH}_{2}$ of THF), $2.10\left(\mathrm{~s}, 12 \mathrm{H}, \mathrm{CH}_{3}\right), 1.22\left(\mathrm{~m}, 12 \mathrm{H}, \beta-\mathrm{CH}_{2}\right.$ of THF). ${ }^{13} \mathrm{C}\left\{{ }^{1} \mathrm{H}\right\}$ NMR (THF- $d_{8}, 21^{\circ}$ C): $160.7(\mathrm{C}=\mathrm{N}), 140.3(\operatorname{aryl}), 124.9(\operatorname{aryl}), 90.2(\alpha-\mathrm{C}), 51.6\left(\mathrm{CH}_{2}\right), 18.5\left(\mathrm{CH}_{3}\right)$. The IR spectrum is included in the Supporting Information.

\section{pBinAl ${ }_{2} \mathrm{Me}_{4}$}

Trimethylaluminum $(0.20 \mathrm{~mL}$ of a $2 \mathrm{M}$ solution in hexanes, $0.40 \mathrm{mmol})$ was added to a solution of $\mathrm{pBinH}_{2}(80 \mathrm{mg}, 0.20 \mathrm{mmol})$ in toluene $(8 \mathrm{~mL})$ at room temperature. After stirring for $12 \mathrm{~h}$, the solution was concentrated to $4 \mathrm{~mL}$ and pentane $(6 \mathrm{~mL})$ was layered above the toluene solution, the vial was cooled to $-38{ }^{\circ} \mathrm{C}$, causing the formation of needles $(117 \mathrm{mg}, 77.0 \%$ yield). Analysis found (calcd.) C, $69.76(70.29) \%, \mathrm{H}, 8.68(8.26) \%, \mathrm{~N}, 9.57(10.93) \% ;{ }^{1} \mathrm{H}$ NMR $\left(\mathrm{C}_{6} \mathrm{D}_{6}, 21^{\circ} \mathrm{C}\right): 6.78(\mathrm{~s}, 8 \mathrm{H}, \mathrm{ArCH}), 4.77(\mathrm{~s}, 2 \mathrm{H}, \alpha-\mathrm{CH}), 4.36\left(\mathrm{~d}, 4 \mathrm{H}, \mathrm{CH}_{2}, 14.4 \mathrm{~Hz}\right), 4.23$ $\left(\mathrm{d}, 4 \mathrm{H}, \mathrm{CH}_{2}, 14.4 \mathrm{~Hz}\right), 1.55\left(\mathrm{~s}, 12 \mathrm{H}, \mathrm{CH}_{3}\right),-0.43\left(\mathrm{~s}, 6 \mathrm{H}, \mathrm{Al}-\mathrm{CH}_{3}\right),-1.11(\mathrm{~s}, 6 \mathrm{H}, \mathrm{Al}-$ $\left.\mathrm{CH}_{3}\right) .{ }^{13} \mathrm{C}\left\{{ }^{1} \mathrm{H}\right\}$ NMR $\left(\mathrm{THF}-d_{8}, 21^{\circ} \mathrm{C}\right): 166.3(\mathrm{C}=\mathrm{N}), 136.3$ (aryl), 126.0 (aryl), $96.0(\alpha-\mathrm{C})$, 47.6 $\left(\mathrm{CH}_{2}\right), 18.5\left(\mathrm{CH}_{3}\right),-14.6\left(\mathrm{Al}-\mathrm{CH}_{3}\right)$. The IR spectrum is included in the Supporting Information.

\section{pBinZn $\mathrm{Et}_{2}$}

Diethylzinc $(0.5 \mathrm{~mL}, 0.5 \mathrm{mmol})$ was added to a solution of $\mathrm{pBinH}_{2}(100 \mathrm{mg}, 0.25 \mathrm{mmol})$ in toluene $(8 \mathrm{~mL})$ at room temperature. After stirring for 3 days, the solvent was removed under vacuum and the product was washed with pentane $(6 \mathrm{~mL})$ to produce a white powder $(108.9$ $\mathrm{mg}, 74.27 \%$ ). Analysis found (calcd.) C, $61.25(61.90) \%, \mathrm{H}, 6.60(7.04) \%, \mathrm{~N}, 9.50$ (9.31)\%. ${ }^{1} \mathrm{H}$ NMR $\left(\mathrm{C}_{6} \mathrm{D}_{6}, 21^{\circ} \mathrm{C}\right): 6.92(\mathrm{~s}, 8 \mathrm{H}, \mathrm{ArCH}), 4.62(\mathrm{~s}, 2 \mathrm{H}, \alpha-\mathrm{CH}), 4.56\left(\mathrm{~d}, 4 \mathrm{H}, \mathrm{CH}_{2}\right.$, $\mathrm{J}=14.8 \mathrm{~Hz}), 4.29\left(\mathrm{~d}, 4 \mathrm{H}, \mathrm{CH}_{2}, \mathrm{~J}=14.8 \mathrm{~Hz}\right), 1.82\left(\mathrm{~s}, 12 \mathrm{H}, \mathrm{CH}_{3}\right), 1.12\left(\mathrm{t}, 6 \mathrm{H}, \mathrm{ZnEt}-\mathrm{CH}_{3}, \mathrm{~J}=8\right.$ $\mathrm{Hz}$ ), -0.91 (q, $4 \mathrm{H}, \mathrm{ZnEt}-\mathrm{CH}_{2}, \mathrm{~J}=8 \mathrm{~Hz}$ ). The IR spectrum is included in the Supporting Information.

\section{Acknowledgments}

This research was supported by the National Institutes of Health (GM-065313). 


\section{References and Notes}

1. (a) Everett GW Jr, Holm RH. J. Am. Chem. Soc 1965;87:2117-2127. (b) Bourget-Merle L, Lappert MF, Severn JR. Chem. Rev 2002;102:3031-3066. [PubMed: 12222981]

2. (a) Radzewich CE, Coles MP, Jordan RF. J. Am. Chem. Soc 1998;120:9384-9385. (b) Fekl U, Kaminsky W, Goldberg KI. J. Am. Chem. Soc 2001;123:6423-6424. [PubMed: 11427072] (c) Yokota S, Tachi Y, Itoh S. Inorg. Chem 2002;41:1342-1344. [PubMed: 11896697] (d) Cope-Eatough EK, Mair FS, Pritchard RG, Warren JE, Woods RJ. Polyhedron 2003;22:1447-1454. (e) Harder S. Angew. Chem., Int. Ed. Engl 2003;42:3430-3434. [PubMed: 12888978] (f) Basuli F, Huffman JC, Mindiola DJ. Inorg. Chem 2003;42:8003-8010. [PubMed: 14632519] (g) Basuli F, Bailey BC, Brown D, Tomaszewski J, Huffman JC, Baik M-H, Mindiola DJ. J. Am. Chem. Soc 2004;126:10506-10507. [PubMed: 15327285] (h) Gregory EA, Lachicotte RJ, Holland PL. Organometallics 2005;24:18031805. (i) Zhu H, Chai J, Jancik V, Roesky HW, Merrill WA, Power PP. J. Am. Chem. Soc 2005;127:10170-10171. [PubMed: 16028919] (j) Reynolds AM, Lewis EA, Aboelella NW, Tolman WB. Chem. Commun 2005:2014-2016. (k) Basuli F, Huffman JC, Mindiola DJ. Inorg. Chim. Acta 2007;360:246-254.

3. (a) Cheng M, Lobkovsky EB, Coates GW. J. Am. Chem. Soc 1998;120:11018-11019. (b) Vollmerhaus R, Rahim M, Tomaszewski R, Xin S, Taylor NJ, Collins S. Organometallics 2000;19:2161-2169. (c) Chisholm MH, Huffman JC, Phomphrai K. J. Chem. Soc., Dalton Trans 2001:222-224. (d) Chamberlain BM, Cheng M, Moore DR, Ovitt TM, Lobkovsky EB, Coates GW. J. Am. Chem. Soc 2001;123:3229-3238. [PubMed: 11457057] (e) Cheng M, Moore DR, Reczek JJ, Chamberlain BM, Lobkovsky EB, Coates GW. J. Am. Chem. Soc 2001;123:8738-8749. [PubMed: 11535078] (f) Gibson VC, Marshall EL, Navarro-Llobet D, White AJP, Williams DJ. J. Chem. Soc., Dalton Trans 2002:4321-4322. (g) Moore DR, Cheng M, Lobkovsky EB, Coates GW. J. Am. Chem. Soc 2003;125:11911-11924. [PubMed: 14505413] (h) Byrne CM, Allen SD, Lobkovsky EB, Coates GW. J. Am. Chem. Soc 2004;126:11404-11405. [PubMed: 15366863] (i) Chisholm MH, Gallucci JC, Phomphrai K. Inorg. Chem 2005;44:8004-8010. [PubMed: 16241150]

4. (a) Fekl U, Kaminsky W, Goldberg KI. J. Am. Chem. Soc 2003;125:15286-15287. [PubMed: 14664561] (b) Bernskoetter WH, Lobkovsky E, Chirik PJ. Chem. Commun 2004:764-765. (c) Bernskoetter WH, Lobkovsky E, Chirik PJ. Organometallics 2005;24:4367-4373.

5. Crimmin MR, Casely IJ, Hill MS. J. Am. Chem. Soc 2005;127:2042-2043. [PubMed: 15713071]

6. Zhao G, Basuli F, Kilgore UJ, Fan H, Aneetha H, Huffman JC, Wu G, Mindiola DJ. J. Am. Chem. Soc 2006;128:13575-13585. [PubMed: 17031972]

7. Vela J, Smith JM, Yu Y, Ketterer NA, Flaschenriem CJ, Lachicotte RJ, Holland PL. J. Am. Chem. Soc 2005;127:7857-7870. [PubMed: 15913376]

8. Park K-H, Bradley AZ, Thompson JS, Marshall WJ. Inorg. Chem 2006;45:8480-8482. [PubMed: 17029355]

9. (a) Dai X, Warren TH. J. Am. Chem. Soc 2004;126:10085-10094. [PubMed: 15303885] (b) Dai X, Kapoor P, Warren TH. J. Am. Chem. Soc 2004;126:4798-4799. [PubMed: 15080682] (c) Badiei YM, Krishnaswamy A, Melzer MM, Warren TH. J. Am. Chem. Soc 2006;128:15056-15057. [PubMed: 17117834] (d) Kogut E, Wiencko HL, Zhang L, Cordeau DE, Warren TH. J. Am. Chem. Soc 2005;127:11248-11249. [PubMed: 16089446]

10. (a) Basuli F, Tomaszewski J, Huffman JC, Mindiola DJ. J. Am. Chem. Soc 2003;125:10170-10171. [PubMed: 12926929] (b) Basuli F, Bailey BC, Tomaszewski J, Huffman JC, Mindiola DJ. J. Am. Chem. Soc 2003;125:6052-6053. [PubMed: 12785824] (c) Basuli F, Bailey BC, Brown D, Tomaszewski J, Huffman JC, Baik M-H, Mindiola DJ. J. Am. Chem. Soc 2004;126:10506-10507. [PubMed: 15327285] (d) Basuli F, Kilgore UJ, Brown D, Huffman JC, Mindiola DJ. Organometallics 2004;23:6166-6175. (e) Basuli F, Kilgore UJ, Hu X, Meyer K, Pink M, Huffman JC, Mindiola DJ. Angew. Chem., Int. Ed 2004;43:3156-3159. (f) Basuli F, Bailey BC, Huffman JC, Mindiola DJ. Organometallics 2005;24:3321-3334. (g) Basuli F, Clark RL, Bailey BC, Brown D, Huffman JC, Mindiola DJ. Chem. Commun 2005:2250-2252. (h) Mindiola DJ. Acc. Chem. Res 2006;39:813821. [PubMed: 17115721]

11. Eckert NA, Vaddadi S, Stoian S, Lachicotte RJ, Cundari TR, Holland PL. Angew. Chem., Int. Ed 2006;45:6868-6871. 
12. (a) Hardman NJ, Cui C, Roesky HW, Fink WH, Power PP. Angew. Chem., Int. Ed 2001;40:21722174. (b) Ding Y, Ma Q, Uson I, Roesky HW, Noltemeyer M, Schmidt H-G. J. Am. Chem. Soc 2002;124:8542-8543. [PubMed: 12121091] (c) Zhu H, Chai J, Chandrasekhar V, Roesky HW, Magull J, Vidovic D, Schmidt H-G, Noltemeyer M, Power PP. J. Am. Chem. Soc 2004;126:94729473. [PubMed: 15291514]

13. (a) Chai J, Zhu H, Stueckl AC, Roesky HW, Magull J, Bencini A, Caneschi A, Gatteschi D. J. Am. Chem. Soc 2005;127:9201-9206. [PubMed: 15969598] (b) Chai J, Zhu H, Stueckl AC, Roesky HW, Magull J, Bencini A, Caneschi A, Gatteschi D. J. Am. Chem. Soc 2005;127:9201. [PubMed: 15969598] (c) Wang Y, Quillian B, Wei P, Wang H, Yang X-J, Xie Y, King RB, Schleyer PVR, Schaefer HF III, Robinson GH. J. Am. Chem. Soc 2005;127:11944-11945. [PubMed: 16117525] (d) Hill MS, Hitchcock PB, Pongtavornpinyo R. Science 2006;311:1904-1907. [PubMed: 16574862]

14. (a) Spencer DJE, Aboelella NW, Reynolds AM, Holland PL, Tolman WB. J. Am. Chem. Soc 2002;124:2108-2109. [PubMed: 11878952] (b) Cramer CJ, Tolman WB, Theopold KH, Rheingold AL. Proc. Nat. Acad. Sci. U. S. A 2003;100:3635-3640. (c) Aboelella NW, Kryatov SV, Gherman BF, Brennessel WW, Young VG Jr, Sarangi R, Rybak-Akimova EV, Hodgson KO, Hedman B, Solomon EI, Cramer CJ, Tolman WB. J. Am. Chem. Soc 2004;126:16896-16911. [PubMed: 15612729] (d) Aboelella NW, Gherman BF, Hill LMR, York JT, Holm N, Young VG, Cramer CJ, Tolman WB. J. Am. Chem. Soc 2006;128:3445-3458. [PubMed: 16522125]

15. (a) Smith JM, Lachicotte RJ, Pittard KA, Cundari TR, Lukat-Rodgers G, Rodgers KR, Holland PL. J. Am. Chem. Soc 2001;123:9222-9223. [PubMed: 11552855] (b) Vela J, Stoian S, Flaschenriem CJ, Münck E, Holland PL. J. Am. Chem. Soc 2004;126:4522-4523. [PubMed: 15070362] (c) Holland PL. Can. J. Chem 2005;83:296-301. (d) Smith JM, Sadique AR, Cundari TR, Rodgers KR, LukatRodgers G, Lachicotte RJ, Flaschenriem CJ, Vela J, Holland PL. J. Am. Chem. Soc 2006;128:756769. [PubMed: 16417365] (e) Stoian SA, Vela J, Smith JM, Sadique AR, Holland PL, Münck E, Bominaar EL. J. Am. Chem. Soc 2006;128:10181-10192. [PubMed: 16881648]

16. (a) Christiansen J, Dean DR, Seefeldt LC. Annu. Rev. Plant Physiol. Plant Mol. Biol 2001;52:269295. [PubMed: 11337399] (b) Seefeldt LC, Dance IG, Dean DR. Biochemistry 2004;43:1401-1409. [PubMed: 14769015] (c) Dos Santos PC, Igarashi RY, Lee H-I, Hoffman BM, Seefeldt LC, Dean DR. Acc. Chem. Res 2005;38:208-214. [PubMed: 15766240]

17. Gavrilova AL, Bosnich B. Chem. Rev 2004;104:349-383. [PubMed: 14871128]

18. Moore DR, Cheng M, Lobkovsky EB, Coates GW. J. Am. Chem. Soc 2003;125:11911-11924. [PubMed: 14505413]

19. Lee SY, Na SJ, Kwon HY, Lee BY, Kang SO. Organometallics 2004;23:5382-5385.

20. Lee BY, Kwon HY, Lee SY, Na SJ, Han S, Yun H, Lee H, Park Y-W. J. Am. Chem. Soc 2005;127:3031-3037. [PubMed: 15740141]

21. Pilz MF, Limberg C, Ziemer B. J. Org. Chem 2006;71:4559-4564. [PubMed: 16749789]

22. Bourget-Merle L, Hitchcock PB, Lappert MF. J. Organomet. Chem 2004;689:4357.

23. (a) Allen SD, Moore DR, Lobkovsky EB, Coates GW. J. Organomet. Chem 2003;683:137-148. (b) Hebden TJ, Brennessel WW, Flaschenriem CJ, Holland PL. Dalton 2006:3855-3857.

24. Busch DH. Acc. Chem. Res 1978;11:392-400.

25. (a) Vitanova DV, Hampel F, Hultzsch KC. J. Organomet. Chem 2005;690:5182-5197. (b) Vitanova DV, Hampel F, Hultzsch KC. Dalton Trans 2005:1565-1566. [PubMed: 15852102]

26. Fandos R, Walter MD, Kazhdan D, Andersen RA. Organometallics 2006;25:3706-3715.and references therein.

27. Cui C, Roesky HW, Schmidt H, Noltemeyer M, Hao H, Cimpoesu F. Angew. Chem. Int. Ed 2000;39:4274-4276.

28. CSD version 5.27, updated August 2006: Allen, F. H. Acta Cryst 2002;B58:380.

29. In the ${ }^{13} \mathrm{C}\left\{{ }^{1} \mathrm{H}\right\}$ NMR spectra, the aluminum-bound carbon atoms are shifted upfield and broadened

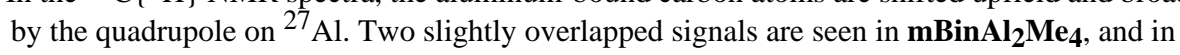
$\mathbf{p B i n A l}_{2} \mathbf{M e}_{4}$ only one signal is seen, presumably because the two signals overlap completely.

30. Averill, BA. Dinuclear Hydrolases. In: McCleverty, J.; Meyer, TJ., editors. Comprehensive Coordination Chemistry II. Vol. 8. Oxford: Elsevier; 2004. p. 641-676. 
31. (a) Nolan EM, Jaworski J, Racine ME, Sheng M, Lippard SJ. Inorg. Chem 2006;45:9748-9757. [PubMed: 17112271] (b) Nolan EM, Ryu JW, Jaworski J, Feazell RP, Sheng M, Lippard SJ. J. Am. Chem. Soc 2006;128:15517-15528. [PubMed: 17132019]

32. (a) Adkins H, Kutz W, Coffman DC. J. Am. Chem. Soc 1930;52:4391. (b) Dorman LC. Tetrahedron Lett 1966:459-464. 


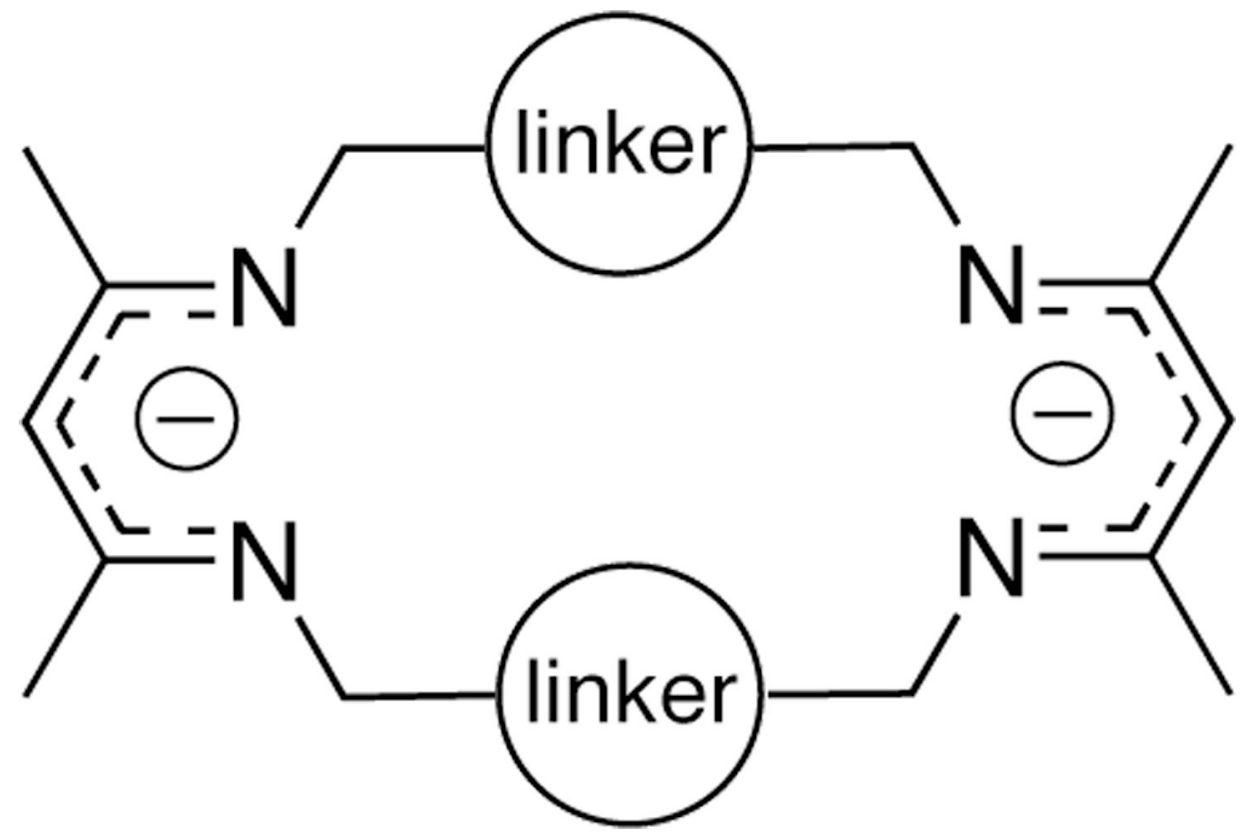

Figure 1.

Template for easily synthesized binucleating ligands Bin, based on the conceptual condensation of 2,4-pentanedione with aromatic xylylenediamines. 


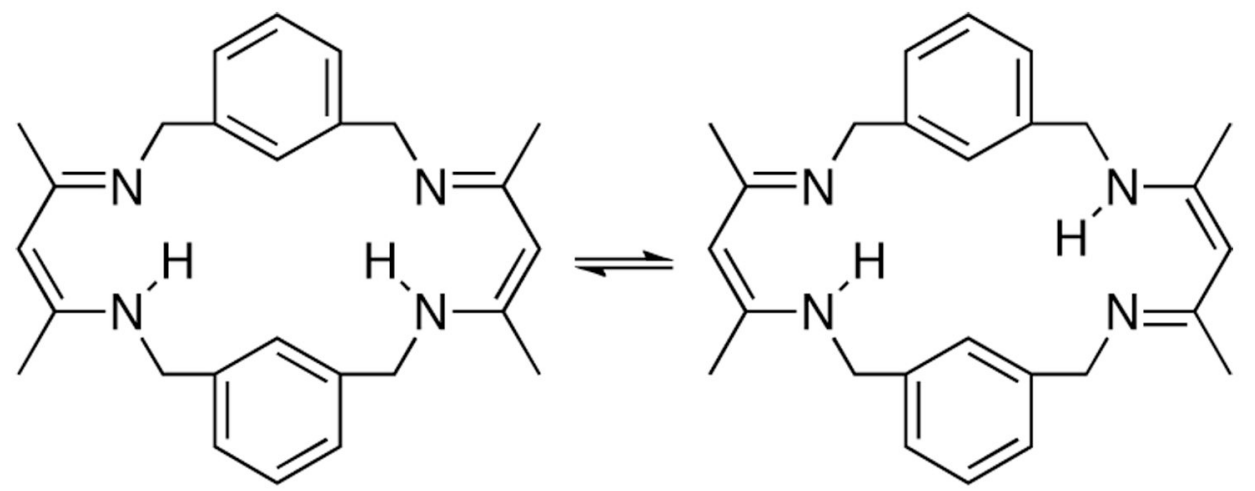<smiles>C=C=C</smiles><smiles>C=CC=C</smiles>

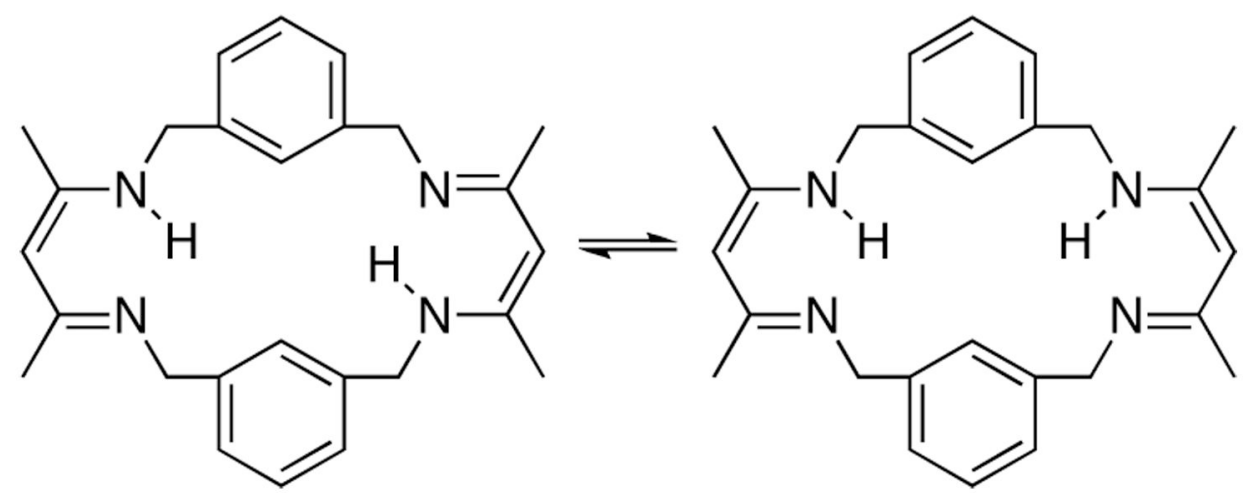

Figure 2.

Tautomers of $\mathbf{m B i n H}_{\mathbf{2}}$. The analogous tautomers are present for $\mathbf{p B i n H _ { 2 }}$. 


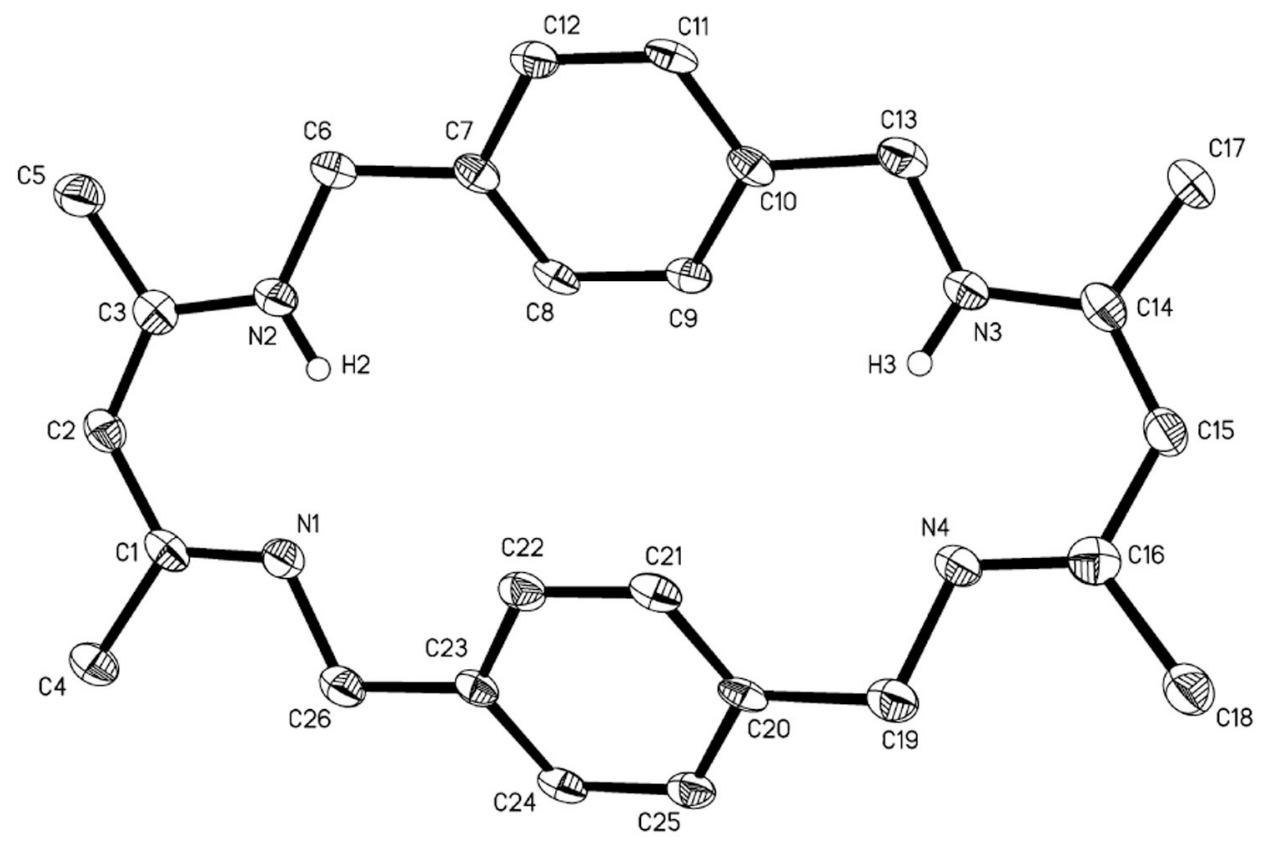

Figure 3.

Thermal-ellipsoid plot of $p \mathrm{BinH}_{2}$ showing $50 \%$ probability ellipsoids. Carbon-bound hydrogen atoms have been omitted for clarity. 


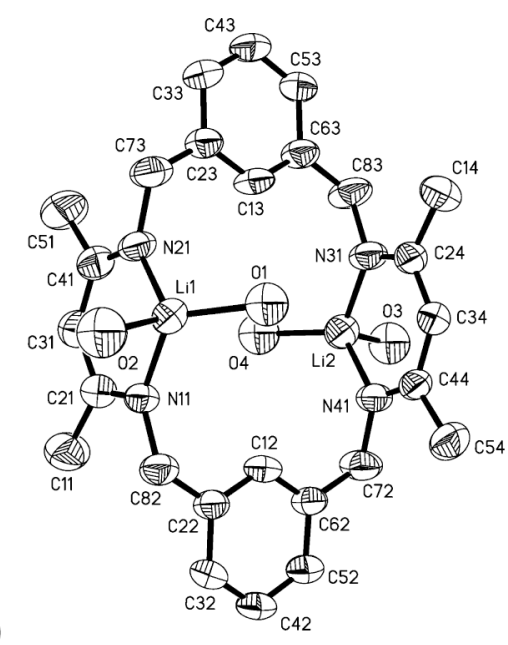

(b)

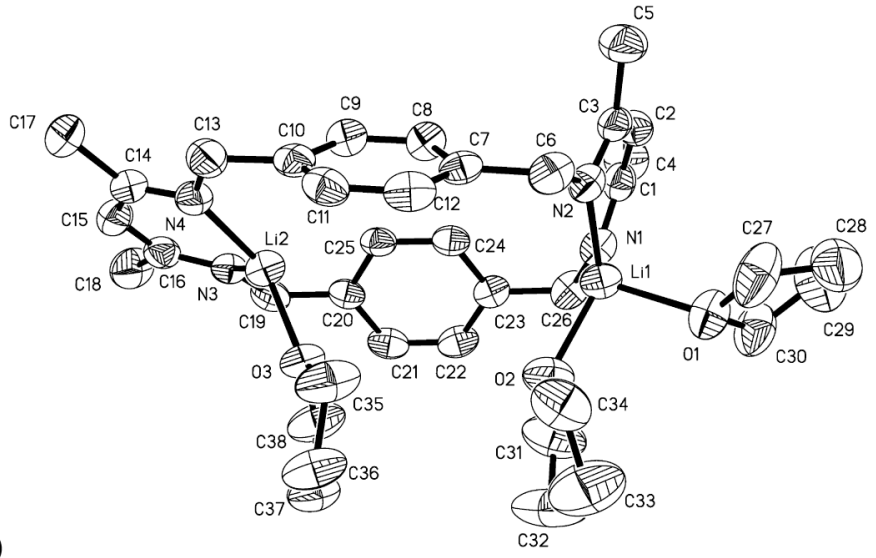

Figure 4.

Thermal-ellipsoid plots of $\mathbf{m B i n L i}_{\mathbf{2}}(\mathbf{T H F})_{\mathbf{4}}$ and of $\mathbf{p B i n L i} \mathbf{i}_{\mathbf{2}}(\mathbf{T H F})_{\mathbf{3}}$, showing $50 \%$ probability ellipsoids. Hydrogen atoms are not shown for clarity. The THF ligands in $\mathbf{m B i n L i} \mathbf{2}_{\mathbf{2}}(\mathbf{T H F})_{\mathbf{4}}$ are highly disordered, and only the oxygen atoms are shown. 

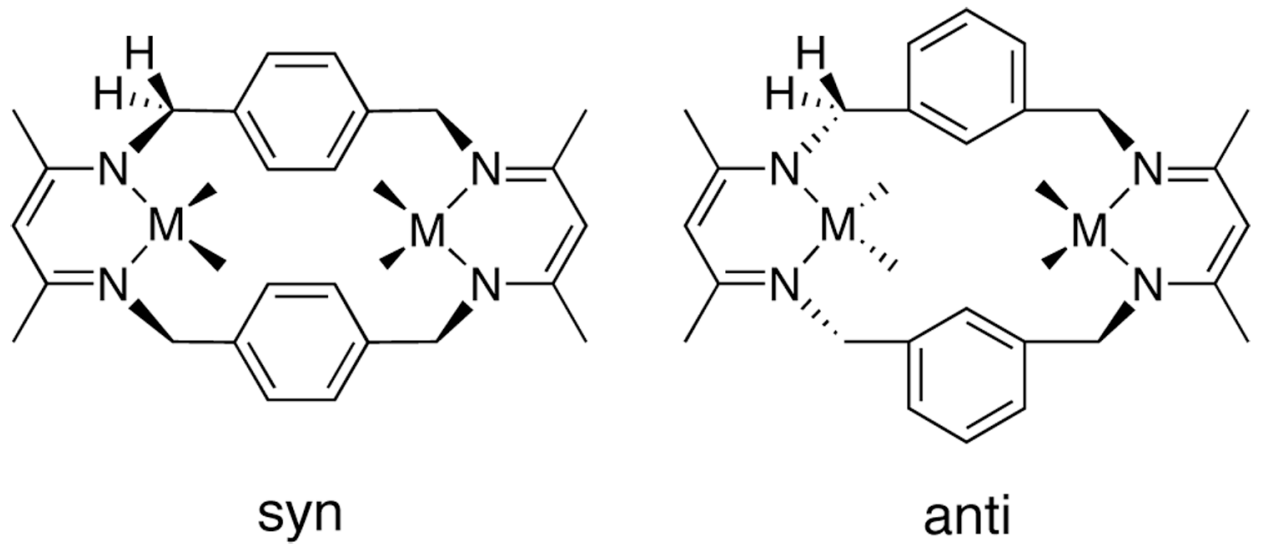

Figure 5.

The different conformations of metal complexes of the binucleating ligands. In the upper left of each structure are shown the two protons that are diastereotopic in complexes for which interconversion of isomers is slow or absent. 


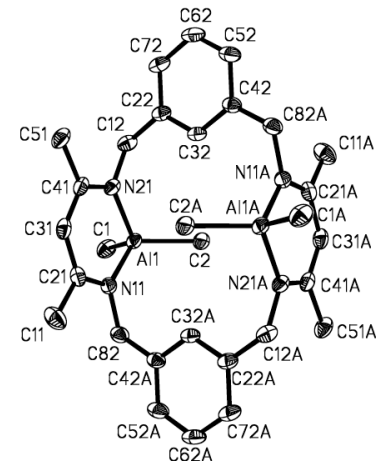

(a)

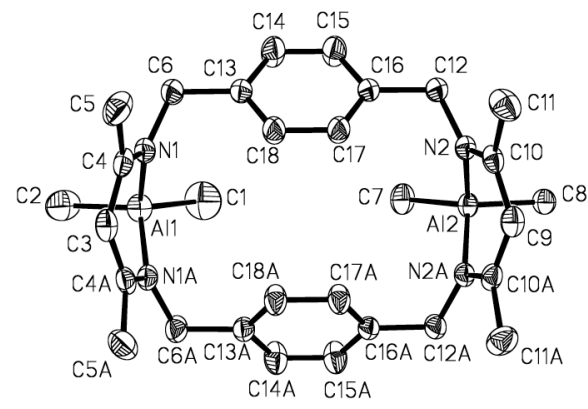

(b)

Figure 6.

Thermal-ellipsoid plots of (a) $\mathrm{mBinAl}_{2} \mathrm{Me}_{4}$ and (b) $\mathrm{pBinAl}_{2} \mathrm{Me}_{4}$ showing $50 \%$ probability ellipsoids. Hydrogen atoms have been omitted for clarity. 


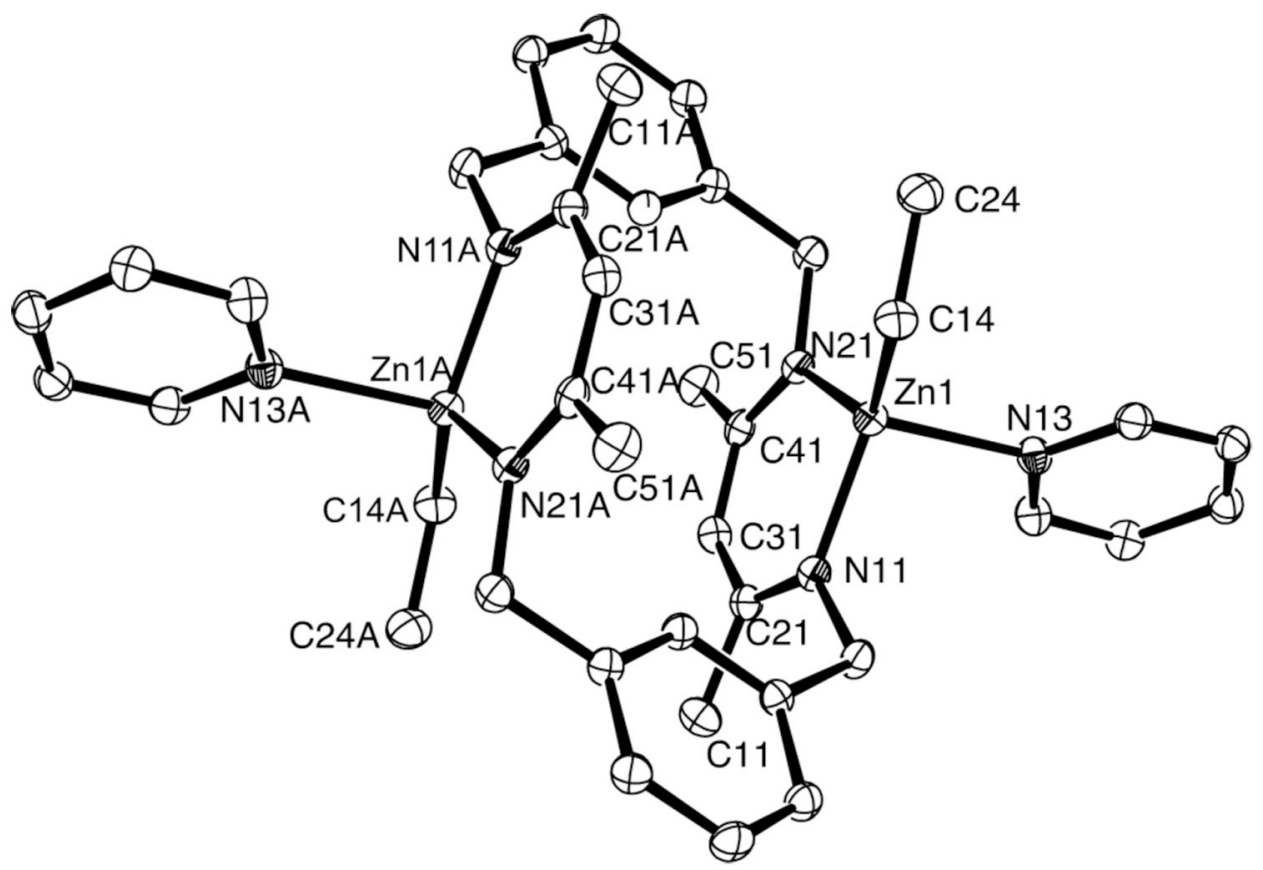

Figure 7.

Thermal-ellipsoid plot of $m \mathrm{BinZn}_{2} \mathrm{Et}_{2} \mathrm{py}_{2}$ showing $50 \%$ probability ellipsoids. Hydrogen atoms have been omitted for clarity. 


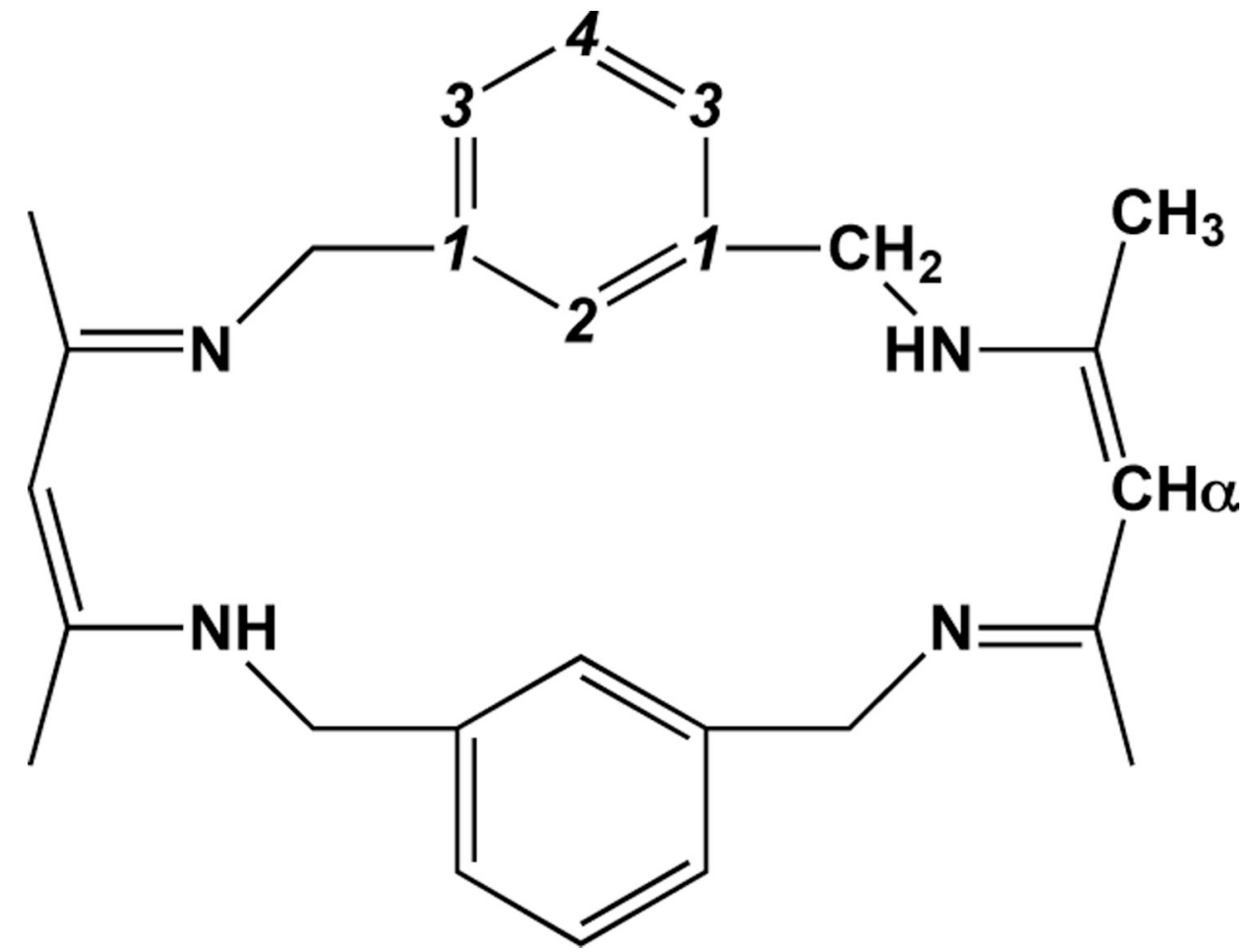

Figure 8.

Numbering scheme for the $m$ Bin ligand. 


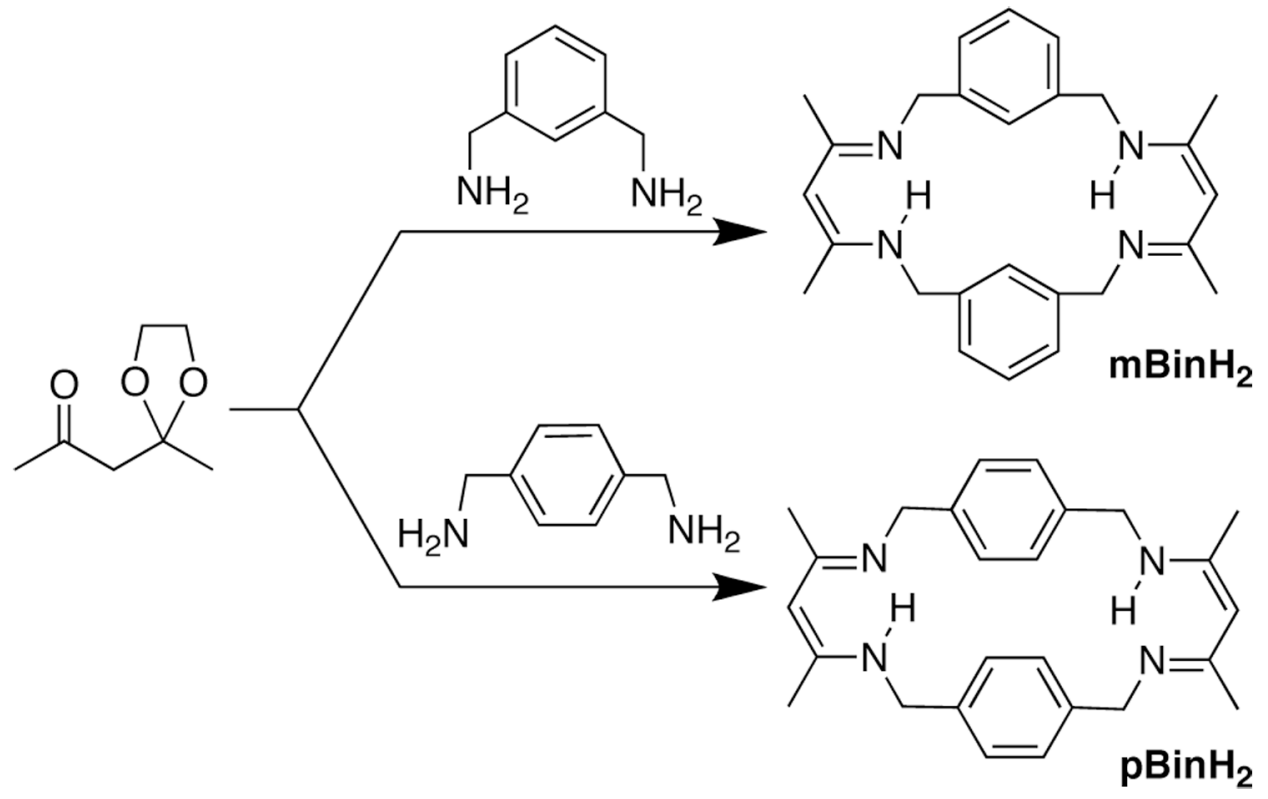

Scheme 1. 
<smiles>CC(C)=CC(C)=Nc1ccc(-c2ccccc2-c2ccc(N/N=C(/C)C=C(C)N=C(C)C)cc2)cc1</smiles><smiles>CCC(C)c1cc(C(C=N[Al])=NC[Al])c2c(c1)C(C)(C)c1cc(CC(C)C)cc(C(C=N[Al])=CN[Al])c1O2</smiles>

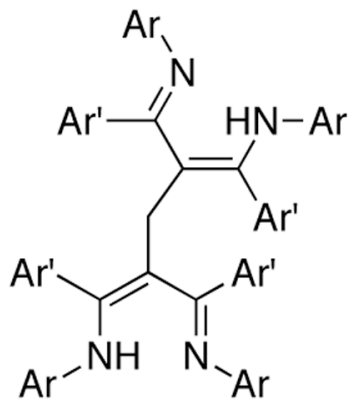

3<smiles>CCN/C(C)=C\C(C)=NC1CCCCC1/N=C(C)/C=C(/C)NCC</smiles>

4

Chart 1. 
Table 1

Selected Bond Lengths $(\AA)$ and Angles (deg) for $\mathbf{p B i n H}_{2}$.

\begin{tabular}{llll}
\hline C3-C5 & $1.497(3)$ & C14-C17 & $1.507(3)$ \\
C2-C3 & $1.380(3)$ & C14-C15 & $1.370(3)$ \\
C1-C2 & $1.436(3)$ & C15-C16 & $1.448(3)$ \\
C1-C4 & $1.509(3)$ & C16-C18 & $1.512(3)$ \\
N2-C3 & $1.347(3)$ & N3-C14 & $1.347(3)$ \\
N1-C1 & $1.304(3)$ & N4-C16 & N3-C14-C15 \\
N2-C3-C2 & $121.8(2)$ & C14-C15-C16 & $1.302(3)$ \\
C3-C2-C1 & $126.2(2)$ & N4-C16-C15 & $126.7(2)$ \\
N1-C1-C2 & $121.1(2)$ & & $120.7(2)$ \\
\hline
\end{tabular}


Table 2

Selected Bond Lengths $(\AA)$ and Angles (deg) for $\mathbf{p B i n L i} \mathbf{2}_{2}$ (THF) $)_{3}$, shown in Fig 4b. The high $R$ value for the structure of $\mathbf{~ m B i n L i}_{2}(\mathbf{T H F})_{4}$ (Fig 4a) suggests that it does not have reliable metrical parameters.

\begin{tabular}{llll}
\hline Li1-N2 & $1.935(6)$ & Li1-N1 & $1.946(6)$ \\
Li2-N4 & $1.921(6)$ & Li2-N3 & $1.929(6)$ \\
Li1-O1 & $2.044(6)$ & Li1-O2 & $1.981(6)$ \\
Li2-O3 & $1.921(5)$ & N3-C16 & $1.320(4)$ \\
N1-C1 & $1.315(4)$ & N4-C14 & $1.322(4)$ \\
N2-C3 & $1.316(4)$ & C14-C15 & $1.397(5)$ \\
C1-C2 & $1.400(5)$ & C15-C16 & $1.406(5)$ \\
C2-C3 & $1.414(5)$ & O2-Li1-O1 & $96.6(2)$ \\
N2-Li1-N1 & $98.6(2)$ & N4-Li2-O3 & $128.0(3)$ \\
N4-Li2-N3 & $98.6(3)$ & & \\
N3-Li2-O3 & $118.9(3)$ & & \\
\hline
\end{tabular}


Table 3

Selected Bond Lengths $(\AA)$ and Angles (deg) for $\mathrm{BinAl}_{2} \mathrm{Me}_{4}$ complexes

\begin{tabular}{llll}
\hline & $\mathbf{m B i n A l}_{\mathbf{2}} \mathbf{M e}_{\mathbf{4}}$ :solvent & $\mathbf{m B i n A l}_{\mathbf{2}} \mathbf{M e}_{\mathbf{4}}$ & $\mathbf{p B i n A l}_{\mathbf{2}} \mathbf{M e}_{\mathbf{4}}$ \\
\hline N-C (diketiminate) & $1.330(2), 1.330(2)$ & $1.333(2), 1.334(2)$ & $1.336(1), 1.334(1)$ \\
C-C (diketiminate) & $1.402(2), 1.399(2)$ & $1.400(2), 1.404(2)$ & $1.399(1), 1.404(1)$ \\
Al-N & $1.897(1), 1.899(1)$ & $1.902(1), 1.902(1)$ & $1.9011(9), 1.9025(8)$ \\
Al-C & $1.971(2), 1.976(2)$ & $1.973(1), 1.902(1)$ & $1.960(2), 1.966(2)$ \\
N-Al-N & $96.14(6)$ & $96.05(4)$ & $95.36(5), 95.98(5)$ \\
C-Al-C & $113.64(8)$ & $113.22(6)$ & $115.40(12), 117.44(7)$ \\
& & & \\
\hline
\end{tabular}


Table 4

Selected Bond Lengths ( $(\AA)$ and Angles (deg) for $\mathrm{mBinZn}_{2} \mathrm{Et}_{2} \mathrm{py}_{2}$

\begin{tabular}{llll}
\hline N11-C21 & $1.324(3)$ & N21-C41 & $1.325(3)$ \\
C21-C31 & $1.411(3)$ & C31-C41 & $1.409(3)$ \\
Zn1- N11 & $2.003(2)$ & Zn1- N21 & $2.006(2)$ \\
Zn1-C14 & $1.995(2)$ & Zn1- N13 & $123.41(8)$ \\
C14- Zn1- N11 & $130.37(8)$ & C14- Zn1- N21 & $107.74(8)$ \\
N11-Zn1- N21 & $95.20(7)$ & N14-Zn1- N13 & $97.99(7)$ \\
N11- Zn1- N13 & $94.68(7)$ & & \\
\hline
\end{tabular}

